\title{
The life of plant mitochondrial complex I
}

Hans-Peter Braun ${ }^{1 *}$, Stefan Binder ${ }^{2}$, Axel Brennicke ${ }^{2}$, Holger Eubel ${ }^{1}$, Alisdair R. Fernie ${ }^{3}$, Iris Finkemeier ${ }^{4}$, Jennifer Klodmannn ${ }^{1}$, Ann-Christine König ${ }^{4}$, Kristina Kühn ${ }^{5}$, Etienne Meyer ${ }^{3}$, Toshihiro Obata ${ }^{3}$, Markus Schwarzländer ${ }^{6}$, Mizuki Takenaka², Anja Zehrmann²

${ }^{1}$ Institut für Pflanzengenetik, Leibniz Universität Hannover, Herrenhäuser Str. 2, 30419 Hannover, Germany

${ }^{2}$ Molekulare Botanik, Universität Ulm, Albert-Einstein-Allee 11, 89069 Ulm, Germany

${ }^{3}$ Max Planck Institute of Molecular Plant Physiology, Am Mühlenberg 1, 14476 Potsdam, Germany

${ }^{4}$ Plant Sciences, Ludwig Maximilians Universität München, Grosshadernerstr. 2-4, 82152 Planegg-Martinsried, Germany

${ }^{5}$ Institut für Biologie/Molekulare Zellbiologie der Pflanzen, Humboldt Universität zu Berlin, Philippstraße 13, 10115 Berlin, Germany

${ }^{6}$ INRES - Chemical Signalling, Rheinische Friedrich-Wilhelms-Universität Bonn, FriedrichEbert-Allee 144, D-53113 Bonn, Germany

* Author for correspondence: H.P.Braun, braun@genetik.uni-hannover.de 


\section{Contents}

1. Introduction

2. Biosynthesis and Assembly ("Birth and Childhood")

2.1. Genes

2.2. Transcription

2.3. Transcript maturation

2.4. Translation

2.5. Import of nuclear encoded subunits

2.6. Assembly, assembly factors

2.7. Architecture and internal subunit arrangement

3. Function \& Regulation ("Adulthood/Maturity")

3.1. Physiological roles of complex I

3.2. Posttranslational modifications

3.3. Protein and lipid interactions of complex I

3.4. ROS formation at complex I

4. Turnover, disassembly and degradation ("Old age and Death")

5. Outlook

\section{Key words}

plant mitochondria

oxidative phosphorylation

oxidoreductase

carbonic anhydrase

RNA editing

reactive oxygen species 
The mitochondrial NADH dehydrogenase complex (complex I) of the respiratory chain has several remarkable features in plants: (i) particularly many of its subunits are encoded by the mitochondrial genome, (ii) its mitochondrial transcripts undergo extensive maturation processes (e.g. RNA editing, trans-splicing), (iii) its assembly follows unique routes, (iv) it includes an additional functional domain which contains carbonic anhydrases and (v) it is, indirectly, involved in photosynthesis. Comprising about 50 distinct protein subunits, complex I of plants is very large. However, an even larger number of proteins are required to synthesize these subunits and assemble the enzyme complex. This review aims to follow the complete "life cycle" of plant complex I from various molecular perspectives. We provide arguments that complex I represents an ideal model system for studying the interplay of respiration and photosynthesis, the cooperation of mitochondria and the nucleus during organelle biogenesis and the evolution of the mitochondrial oxidative phosphorylation system.

\section{Introduction}

The NADH dehydrogenase complex was first characterized in bovine mitochondria (Hatefi et al., 1962). Over 50 years ago, Hatefi and co-workers systematically studied the structural basis of "cellular respiration" - the transfer of electrons from mitochondrial substrates to molecular oxygen. Using biochemical fractionation procedures they could show that respiration can be subdivided into four segments (reviewed in Hatefi, 1985). Upon their re-constitution, respiration was re-established. In contrast, further fractionation of the individual segments caused irreversible loss of respiratory activity. Therefore, the segments were considered to represent the smallest physiological units of respiration. Physically, all of them represent protein complexes: the NADH dehydrogenase complex (complex I), the succinate dehydrogenase complex (complex II), the cytochrome c reductase complex (complex III) and the cytochrome c oxidase complex (complex IV). Together, the complexes I to IV form the respiratory electron transfer chain, which catalyzes electron transfer from NADH or FADH ${ }_{2}$ to molecular oxygen.

The respiratory chain is linked to synthesis of ATP by an indirect mechanism first suggested by Peter Mitchell (1961): respiratory electron transport causes formation of a proton gradient across the inner mitochondrial membrane which is subsequently used by another protein complex, the ATP synthase (also known as complex V), to catalyze phosphorylation of ADP. Indeed, complexes I, III and IV of the respiratory chain not only are oxidoreductases but also proton translocators. In most eukaryotes, ATP synthesis coupled to oxygen reduction by the respiratory chain ("oxidative phosphorylation") is of central importance. It has been calculated that about $65 \mathrm{~kg}$ ATP are produced by this process per day in an average human (Rich, 2003). Approximately $40 \%$ of the protons needed for ATP synthesis by oxidative phosphorylation are supplied by mitochondrial complex I (Watt et al., 2010).

Complex I is a major entry site for electrons into the respiratory chain. It transfers electrons from NADH to ubiquinone. Complex I was already present in the ancestors of mitochondria, the proteobacteria, and as such is considered to have arisen early in evolution (Gray, 2012). Bacterial complex I has a comparatively simple subunit composition and has been studied extensively. Very recently, the structure of complex I from the eubacterium Thermus thermophilus was resolved by Xray crystallography (Baradaran et al., 2013; Sazanov et al., 2013). Complex I is an L-shaped particle (Figure 1). It is composed of two elongate domains, also termed 'arms': the membrane arm, which is 
inserted into the inner mitochondrial membrane, and the peripheral arm, which protrudes into the mitochondrial matrix. Physiologically, complex I can be divided into three functional modules: the $\mathrm{NADH}$ oxidation and the quinone reduction modules ( $\mathrm{N}$ and $\mathrm{Q}$ modules), both localized in the peripheral arm, and the proton transfer module ( $\mathrm{P}$ module) which equals the membrane arm. Based on the crystal structure of bacterial complex I a mechanism for the coupling of electron transfer and proton translocation has been postulated (see section 3.1.; Baradaran et al., 2013; Brandt, 2013).

Like its prokaryote counterpart, mitochondrial complex I is also L-like shaped as revealed by electron microscopy (EM) analyses (Leonard et al., 1987; Guénebaut et al., 1997; Grigorieff, 1998). However, its composition is more complex. While the minimal bacterial complex I consists of 14 subunits, the eukaryotic enzyme is composed of more than 40 different proteins, e.g. 44 subunits in bovine mitochondria (Carroll et al., 2006; Balsa et al., 2012). Most of the complex I subunits present in other eukaryotes represent homologs of the bovine subunits (Cardol, 2011) but nomenclature of subunits unfortunately varies in different species. In this review, the bovine nomenclature is adopted since complex I subunits have been studied extensively in this species. In addition, commonly used alternative nomenclatures are provided in the appendix of our article (Supp. tables 1 and 2).

In plants, complex I biology is particularly intriguing. Besides oxidative phosphorylation, plants generate large amounts of ATP in their chloroplasts during photosynthesis by photophosphorylation (light dependent phosphorylation of ADP). Mechanistically, this process resembles oxidative phosphorylation as it is based on a proton gradient (across the thylakoid membrane) exploited by an ATP synthase complex. However, generation of the proton gradient is driven by electrons coming from the two photosystems. Chloroplasts also include an NAD(P)H dehydrogenase complex. This complex is low in abundance as compared to mitochondrial complex I and is functionally involved in a cyclic electron transport around photosystem I (Shikanai, 2007). It therefore has a distinct physiological role and is outside of the focus of this review.

In plants, the biology of mitochondrial complex I takes place at the functional interface between respiration and photosynthesis. In addition, and this is relevant for complex I in all eukaryotes, it takes place at the functional interface of the mitochondria and the cell nucleus. In bovine mitochondria, seven out of the 44 complex I subunits are encoded by the mitochondrial genome, while the other 37 subunits are nuclear encoded, synthesized on cytosolic ribosomes and transported into the organelle (Balsa et al., 2012; Carroll et al., 2006). In most plants, two additional complex I subunits are encoded on the mitochondrial genome (Unseld et al., 1997). Furthermore, mitochondrial complex I transcripts undergo extensive maturation processes such as RNA editing or trans-splicing, which do not occur in any animal system studied so far. These processes are mainly catalyzed by nuclear encoded proteins which additionally have to be imported from the cytosol. How is protein biosynthesis in the mitochondrial matrix regulated by the nucleus of the plant cell?

Plant complex I represents an ideal model system for studying the nuclear-mitochondrial cooperation as well as for analyzing the molecular interplay of respiration and photosynthesis. It is of limited complexity with about 50 protein constituents, but further proteins are involved in its biosynthesis and assembly. Several aspects of its biology have been extensively studied from various angles. In this review we aim to integrate different lines of research by following "the life cycle of plant complex I" from the biosynthesis of its parts, over its assembly and its function to its disassembly and degradation. 


\section{Biosynthesis and Assembly ("Birth and Childhood")}

Complex I follows a long and remarkably intricate route to become functionally active: approximately fifty genes have to be transcribed in a coordinated manner in two different cellular compartments, the nucleus and the mitochondrion, these transcripts have to be translated in the cytosol or in the mitochondrial matrix, products of cytosolic translation have to be transported into mitochondria and their presequences have to be removed, subunits have to fold correctly and become equipped with the prosthetic groups necessary for enzymatic activity and, finally, subunits have to assemble to form the active holo-complex. To make things even more complex, mitochondrial transcripts undergo extensive maturation processes and translation products require posttranslational modifications. The following sections describe the extraordinary route by which complex I becomes a functionally active protein complex.

\subsection{Genes}

\section{Mitochondrial genes}

The first coding sequences for complex I subunits in the mitochondrial genome of plants were identified about 25 years ago by similarity to their homologs in mammalia and fungi. In watermelon, sequences with features of ND1 (Stern et al., 1986) and in Oenothera berteriana similarities to ND5 were first observed (Wissinger et al., 1988). However, both initial gene models turned out to be incomplete. It took several more years to unravel the respective complete genes: they are fragmented with exons spread through the genome. In fact, the three open reading frames of the nad1, nad2 and nad5 genes need to be assembled by trans-splicing from genomically unconnected mRNAs. The connection between the adjacent exons is made via assembly of the intervening halves of group II introns which somehow find their fitting counterparts in the other RNA molecule and form the secondary (and tertiary) structure to join the two exons (Binder et al., 1992; Chapdelaine and Bonen 1991; Knoop et al., 1991; Wissinger et al., 1991).

These complex arrangements were ultimately proven by CDNA sequence analyses of the respective mature mRNAs. From these the complete open reading frames were deduced even though identifying similarity with homologs in animals and fungi is usually restricted to certain domains of the proteins. While in animals seven subunits (ND1-ND6 plus ND4L) are encoded in the mitochondrial genomes, plant mitochondrial DNA usually codes for nine subunits, ND1-7, ND4L and ND9. 'Usually encoded in the mitochondrial genome' means that in some plant species one or the other of these genes has moved to the nuclear genome. For example, in the liverwort Marchantia polymorpha, the nad7 gene is present in the mitochondrial genome only as a pseudogene while a functional copy of nad7 is located in the nuclear genome (Kobayashi et al., 1997).

Some of the smaller complex I subunit genes are continuous reading frames, but most of the larger mitochondrially encoded complex I subunits are interrupted by group II introns in trans- as well as in cis-configurations. In fact, most of the mitochondrial introns are found in these genes (Bonen, 2008; Unseld et al., 1997). It has been speculated that this concentration of introns in complex I genes may be connected to a regulatory mechanism which controls respiratory functions in plant mitochondria from the nucleus-cytosol compartment. Through this pathway expression of the mitochondrially encoded subunits could be collectively coordinated with the nuclear encoded polypeptides during development and/or in reply to stress situations (Bonen, 2008). Part of this as yet hypothetical 
pathway could be the nuclear encoded freestanding maturase genes which are required for splicing of the mitochondrial complex I introns. However, the functional and evolutionary assembly of this concentration of introns presently merely remains as an observation which needs to be substantiated through further experimental investigation.

\section{Nuclear genes}

According to the most recent proteomic analysis, complex I from Arabidopsis consists of at least 49 different subunits (see section 2.7.; Peters et al., 2013), nine of which are encoded by the mitochondrial genome. The genes encoding the remaining 40 subunits are localized in the nucleus. Seven of the 40 subunits occur in pairs of isoforms. This adds up to 47 currently known complex I genes in the nucleus in Arabidopsis thaliana (Supp. Table 1). These genes are spread across the genome in Arabidopsis: eleven genes are localized on chromosome I, ten on chromosomes II and III, respectively, five on chromosome IV and eleven on chromosome V. Besides the nine mitochondrially encoded subunits, five of the nuclear encoded complex I subunits belong to the minimal set of 14 complex I proteins present in bacteria (the $75 \mathrm{kDa}, 51 \mathrm{kDa}, 24 \mathrm{kDa}$, TYKY and PSST subunits). During evolution, genes encoding these proteins were transferred from the ancestral mitochondrial genome to the nuclear DNA. The remaining genes encode subunits which most likely became part of mitochondrial complex I after the development of the eukaryotic cell. This probably occurred early in evolution because the set of nuclear encoded complex I subunits is largely identical in animal and plant mitochondria (Cardol, 2011). In fact, homologs of 40 of the 49 complex I subunits of Arabidopsis likewise form part of bovine complex I (Peters et al., 2013). The seven pairs of complex I isoforms probably arose by gene duplication events. The two copies of the pairs are localized on different chromosomes in all but one case.

\subsection{Transcription}

\section{Nuclear transcription}

Nuclear genes for complex I subunits show only minor variations in transcript levels between photosynthetic and non-photosynthetic tissues (Lee et al., 2008). Together with the finding that transcripts for mitochondrial proteins and transcripts required for energy metabolism have relatively long half-lives (Narsai et al., 2007), this implies that transcription of nuclear complex I subunit genes is relatively stable. Enhanced transcript levels seen in meristematic and reproductive tissues for mitochondrial proteins have been attributed to an overall stimulation of mitochondrial biogenesis due to increased energy demands (Brennicke et al., 1999). The constitutive nature of complex I gene transcription contrasts with the light- and stress-induced transcription of genes for alternative NAD(P)H dehydrogenases (see section 3.1.; Millar et al., 2011).

Preliminary data suggest the response regulator ARR2 controls transcription of genes encoding complex I subunits (Lohrmann et al., 2001). Expression of nuclear genes for complex I subunits also likely involves transcription factors of the TCP family. An in silico survey revealed that specific cisacting regulatory elements recognized by these factors were over-represented in the promoter regions of nuclear genes for the mitochondrial oxidative phosphorylation (OXPHOS) system in Arabidopsis (Welchen and Gonzalez, 2006). These elements, which are referred to as site II, were shown to control transcription of several genes for mitochondrial proteins (Giraud et al., 2010). Site II 
elements were also detected in promoters of numerous complex I genes in both Arabidopsis and rice (Welchen and Gonzalez, 2006). Their role in controlling complex I biogenesis has, however, not yet been experimentally explored.

Besides genes for complex I subunits, complex I biogenesis requires hundreds of genes for mitochondrial protein import, mitochondrial gene expression and other steps of OXPHOS biogenesis. The modes of transcriptional control of these genes, whose expression mostly peaks during germination (Law et al., 2012; Narsai et al., 2011), will have to be discussed elsewhere.

\section{Mitochondrial transcription}

In addition to genes for nine complex I subunits, plant mitochondrial genomes contain genes for subunits of several other OXPHOS complexes, proteins required for cytochrome maturation and a few components of the mitochondrial translational apparatus (Unseld et al., 1997). For complex I biogenesis, correct expression of the latter is also necessary. As for nuclear complex I genes, transcript levels for complex I genes in mitochondria have been described as stable. Interestingly, diurnal changes in the transcription of all mitochondrial genes, including complex I genes, have been reported but were found to not affect steady-state mitochondrial transcript levels (Okada and Brennicke, 2006).

Complex I genes are generally not clustered in plant mitochondrial genomes. Only in a few cases neighboring complex I genes can be co-transcribed. Moreover, nad1, nad2 and nad5 each have five exons that are located in different genomic regions and joined through trans-splicing following their separate transcription (see above). Earlier studies of mitochondrial transcription and potential regulatory mechanisms controlling this process mostly focused on the architecture and distribution of mitochondrial promoters (Dombrowski et al., 1999; Fey and Marechal-Drouard, 1999; Forner et al., 2007; Kühn et al., 2005). These studies revealed that in most cases, each mitochondrial gene is transcribed from multiple promoters. Mitochondrial promoter sequences, which extend over approximately 20 nucleotides comprising the transcription start site, are only moderately conserved. Importantly, no promoter elements have been identified that are specific for subsets of mitochondrial genes, such as complex I genes. Therefore, mitochondrial promoters are likely to predominantly facilitate transcription initiation rather than transcriptional regulation of mitochondrial gene subsets. This is in agreement with the observation that plant mitochondrial genomes frequently recombine and thus evolve structurally with high rate, resulting in divergent upstream sequences and promoters of mitochondrial genes in different species (Choi et al., 2012).

Mitochondrial genomes are transcribed by nucleus-encoded bacteriophage-type RNA polymerases (Liere et al., 2011). Cereals and other monocots have one mitochondrial RNA polymerase named RPOTm whereas eudicot mitochondria have acquired a second RNA polymerase named RPOTmp. This enzyme is also present in plastids. Distinct roles of these enzymes in species with multiple mitochondrial RNA polymerases have so far been investigated in the model plant Arabidopsis through in vitro transcription assays with recombinant RPOTm and RPOTmp enzymes (Kühn et al., 2007) or reverse-genetic approaches (Kühn et al., 2009). RPOTm recognizes diverse mitochondrial promoter sequences in vitro and has been proposed to be involved in transcription of most, if not all, mitochondrial genes. Inactivation of the RPOTm gene is lethal, substantiating a central role for this enzyme in mitochondrial transcription and OXPHOS biogenesis. Arabidopsis plants lacking a functional RPOTmp gene show reduced, but not completely disrupted, transcription of distinct 
mitochondrial genes, including complex I subunit genes nad1, nad2, nad4, nad5, nad6 and nad9. In contrast, transcription of nad3, nad4L and nad7 is entirely maintained through RPOTm. Together with the complex IV subunit gene cox1, nad6 depends most strongly on RPOTmp, causing severely reduced levels of complexes I and IV in rpoTmp mutants. It was therefore proposed that while RPOTm transcribes all mitochondrial genes, RPOTmp additionally transcribes a subset of mitochondrial genes and specifically affects complex I and IV biogenesis. Mapping of promoters for RPOTmp-dependent genes did not identify RPOTmp-specific promoter sequences, raising the question of how gene specificity of mitochondrial RNA polymerases is controlled. Remarkably, independently transcribed nad1, nad2 or nad5 exons also depend on RPOTmp to varying extent. Therefore, different transcriptional mechanisms participate in transcribing these genes, which adds to the complexity of mitochondrial complex I gene transcription. Different transcriptional mechanisms in complex I gene expression are supported by a recent transcriptomic study of mitochondrial biogenesis during seed germination (Law et al., 2012) and an earlier mitochondrial genome-wide transcriptional survey (Giege et al., 2000). The latter study used run-on transcription assays and found significantly different transcription rates for individual genes encoding subunits of the same protein complex, with nad4L strongly exceeding transcription of other complex I genes. Steady-state transcript levels were considerably more homogeneous, presumably due to transcript stability effects.

Central questions emerging from these observations are: i) How are activity and gene specificity of mitochondrial RNA polymerases controlled? ii) Does the RNA polymerase RPOTmp present a mechanism for specifically regulating the biogenesis of complexes I and IV in response to developmental or environmental cues? High-resolution RPOTm- and RPOTmp-specific transcriptomes, which can be generated using resources available for the dicot model species Arabidopsis, will help in addressing these questions. For future research targeting different modes of complex I gene transcription in dicot versus monocot mitochondria, comparisons of high-resolution mitochondrial transcriptomes and promoters between monocot and dicot species would provide important groundwork.

\subsection{Transcript maturation}

\section{Splicing of mitochondrial nad mRNAs}

Evidence for effective regulation of mitochondrial gene expression is still relatively weak and to date it remains unclear as to whether there are regulatory mechanisms influencing expression of mitochondrial genes. That said the importance of the various post-transcriptional processes for the formation of mature RNAs is unquestionable and processes such as splicing, RNA editing and transcript end maturation provide options for regulation. In seed plants, the nad4 gene contains three introns (nad4i1 to i3), while the nad1, nad2, nad5 and nad7 genes are split by four introns (i1 to i4). These intervening sequences are classified as group II introns, which are spliced by a two-step transesterification pathway (Bonen, 2008). Typically this ribozymic intron class encodes factors required for splicing, but in seed mitochondria a matR gene encoding a reverse transcriptase like protein (maturase) is found only in nad1i4 (Bonen, 2008). A secondary structure with six helical domains (I to $\mathrm{VI}$ ) has been proposed for group II introns, but many plant mitochondrial introns lack classical characteristics of this intron type (Bonen, 2008). Fragmentation of the nad1, nad2 and nad5 
genes into different pieces is one of the most exceptional features of mitochondrial-encoded genes. Translatable transcripts of these genes have to be assembled by trans-splicing of independently transcribed RNAs encoded at distant genomic locations. Trans-spliced introns fold into group II intron structures that are disrupted in domain IV (Bonen, 2008). Several RNA editing sites have been identified in intron sequences, a few of them correcting non-canonical base pairs into classical $A-U$ pairs as for instance in nad1i1 and nad7i4. In vitro experiments with a yeast autocatalytic intron containing domain $\mathrm{VI}$ of the Oenothera nad1 $\mathrm{i} 3$ and in organello studies of trans-spliced nad1i4 and nad5i2 of wheat demonstrated that RNA editing has to precede splicing (Bonen, 2008; Farré et al., 2012). However, it has also been found that excised introns are only partially edited. Thus it seems that RNA editing of particular sites is a prerequisite for splicing while in other cases $\mathrm{C}$ to $\mathrm{U}$ exchanges may merely increase splicing efficiency (Bonen, 2008).

In Arabidopsis, several proteins were found to be involved in mitochondrial splicing (Table 1). The DEAD-box RNA helicase PMH2 has a general supporting role in splicing of various transcripts including nad mRNAs (Köhler et al., 2010). Similarly, a relaxed substrate spectrum was reported for mCSF1, an RNA binding protein required for efficient splicing of various introns (Zmudjak et al., 2013). Broad substrate specificity has also been reported for DEXH-box RNA helicase ABO6 identified in a screen for abscisic acid (ABA) overly-sensitive mutants. In the absence of this protein, splicing efficiency of several introns of different nad transcripts is severely impaired (He et al., 2012). Nuclear-encoded factors homologous to the mitochondrial-encoded MATR are involved in the intron removal from various nad mRNAs (nMAT1 for nad1i1, nad2i1 and nad4i2; nMAT2 for nad1i2 and nad7i2) (Keren et al., 2012). Likewise, RUG3, a protein related to human guanine nucleotide exchange factor, is an important but not essential factor for splicing of nad2i3 (Kühn et al., 2011). Besides these factors, three PPR proteins were found to be involved in splicing of different nad transcripts. OTP43 is essential for splicing of the trans-spliced nad1i1 (Falcon de Longevialle et al., 2007). BIR6, found in a mutant screen for root growth in the presence of the glutathione synthesis inhibitor buthionine sulfoximine, is a splicing factor involved in the removal of nad7i1 (Koprivova et al., 2010). ABO5, identified in the same screen as ABO6, participates in splicing of the nad2i3. Many mutants with defects in splicing of nad transcripts exhibit severely impaired complex I assembly and activity and show visual phenotypes such as retarded growth or curled leaves. Several of the proteins described above are involved in both cis- and trans-splicing events suggesting that there is no fundamental difference between the splicing mechanisms of these introns. Most of these factors may directly bind to RNA, but their exact molecular functions in the splicing process are unclear. Remarkably, the identification of two splicing factors in a screen for ABA overly-sensitive mutants suggests a link between mitochondrial gene expression and ABA signalling.

\section{Processing of mitochondrial transcript extremities}

Another major step towards the formation of mature mitochondrial RNA is the post-transcriptional generation of 5' and 3' ends. In Arabidopsis, two mitochondrial 3' to 5' exoribonucleases (polynucleotide phosphorylase (PNPase) and RNase R homolog 1 (RNR1)) have been identified which appear to be required for the generation of 3 ' termini of the majority of mitochondrial-encoded RNAs including nad transcripts (Perrin et al., 2004) (Table 1). Additionally, MTSF1, a PPR protein involved in the generation of the $+303^{\prime}$ terminus of nad 4 mRNA has been characterized. Similar to a mechanism found in chloroplasts, this protein binds to the 3 ' terminal region of the nad4 mRNA, thereby protecting the transcript from degradation by the mitochondrial PNPase (and RNR1) and concomitantly defining the $3^{\prime}$ end of the mRNA (Haili et al., 2013). Interestingly, this protein is also 
involved in splicing of nad2 RNAs. In contrast, several factors, exclusively P-class PPR proteins, are required for the generation of mature 5 ' termini (Table 1). RNA PROCESSING FACTOR1 (RPF1) and the not yet identified RPF7 seem to be exclusively involved in processing for nad4 and nad2 5 ' termini, respectively, while RPF2 and RPF5 are not only required for formation of mature nad9 and nad6 5' ends, but also for cox3, atp9 and rrn26 RNAs (Hauler et al., 2013; Hölzle et al., 2011; Jonietz et al., 2010). As for the proteins involved in RNA splicing the precise molecular function of the RPF is unknown. It is assumed that they bind to the target RNA in a sequence-specific manner thereby recruiting a potential endonuclease to the cleavage site. In general, plant lines (mutant or accessions) with defective RPFs are indistinguishable from wild type or show reduced seed germination capacity like the rpf5-1 knockout mutant (Hauler et al., 2013). How mitochondrial 5' processing influences seed germination will be subject of future studies that might bring up deeper insights into the importance of this post-transcriptional maturation step in the regulation of plant mitochondrial functions.

\section{RNA editing of mitochondrial transcripts}

Expression of the complex I subunit genes in the mitochondrial genome is not only complicated by the interruption by group II introns in trans- as well as in cis-configurations, but their coding sequences are also modified post-transcriptionally by RNA editing (For a review: Takenaka et al., 2008, 2013). In the model plant Arabidopsis thaliana a total of about 500 RNA editing events alter coding sequences in the mitochondria. Nearly 200 editing events occur in the RNAs for complex I subunits (Table 2). Some RNA editing events in intron sequences are required for correct folding and splicing of these introns (Börner et al., 1995). However, most RNA editing events occur in exons and alter the triplet identity to code for a different amino acid than the one predicted by the genomic DNA.

The extent of RNA editing in the mitochondrial complex I genes is in the intermediate range as compared to other mitochondrial genes. The group of genes coding for heme-cluster biosynthesis factors are much more extensively edited while the mRNAs for subunits of complex III or of the ATPase are usually less altered by the $C$ to $U$ RNA editing process. Again, why the mRNAs for individual subunits of a certain complex are treated to a similar, yet unique, extent by splicing or editing remains unanswered. Speculations such as a common control of half-life and/or translational speed with associated similar time spans remain to be investigated.

Numerous nuclear genes are required for processing the RNA editing events, most notably a number of PPR protein coding genes have been identified to be required for individual or very few editing sites. Up to now, 19 editing factors could be assigned to editing events in complex I transcripts (Table $3)$. Whether any of these proteins is used by the nucleus-cytosol compartment to exert control over gene expression in mitochondria remains an open question. It is unlikely that many of the PPR proteins are involved as their expression levels are very low. However, this feature could also allow fine tuning of these limiting factors. Here only those few at crucial editing sites could function in any sort of control since many editing events will not yield a gross phenotypic effect. Such potential fine tuning does not extend to a variation in polypeptide composition since e.g. the protein sequence of ND9 of complex I contains only the protein corresponding to fully edited mRNA although at one of the non-silent sites only about half of the steady state mRNA is actually edited. 
Expression of nuclear genes encoding subunits of the NADH dehydrogenase complex is controlled at the transcriptional level. Whether there is any substantial contribution of post-transcriptional processes like intron splicing or polyadenylation to the expression regulation of nuclear complex I genes has not yet been specifically addressed in plants. Likewise, it is unknown whether any of the small RNA pathways control such genes but data mining of genome wide studies might shed some light on the post-transcriptional maturation or nuclear-encoded complex I transcripts.

\subsection{Translation}

Basically nothing is known about common features and control of translation events specific to complex I genes in both mitochondria and the cytosol. The absence of a mitochondrial in vitro translation system has hampered such analyses in this compartment. A recent study of a silenced nuclear gene for a mitochondrial ribosomal protein suggests that there may be a regulatory feedback from translational activity to mitochondrial mRNA abundance (Kwasniak et al., 2013). Here differential mRNA levels were observed between the respiratory chain complexes with complex I and complex IV subunit mRNAs being stronger elevated than that of complex III for example.

In the nucleus/cytosol so far no specific investigations of complex I mRNAs and their transport to the vicinity of the mitochondrial outer membranes have been initiated. It will be interesting to see whether polysomes with mRNAs specifying complex I subunits associate at similar regions at the mitochondrial surface and if their translational progress is in any way controlled and coordinated.

\subsection{Import of nuclear encoded subunits}

All nuclear-encoded mitochondrial proteins have to be imported into mitochondria after the precursor proteins have been synthesized on cytosolic ribosomes and guided by chaperones to the organelle surface for import. So far 47 nuclear-encoded complex I proteins have been identified by mass spectrometry in Arabidopsis mitochondria (Suppl. table 1) and five of them were also confirmed to be targeted to mitochondria by C-terminal GFP fusions (Abu-Abied, 2009; Lee et al., 2002; Murcha et al., 2007; Tian et al., 2004; Tanz et al., 2013; Wang et al., 2012a). Depending on the intra-organellar localization, mitochondrially targeted proteins contain either $\mathrm{N}$-terminal presequences or internal non-cleavable signal sequences which are recognized by the protein import receptor TOM20 at the surface of the outer mitochondrial membrane (Rimmer et al., 2011; Schleiff and Becker, 2011). Proteins containing a presequence are usually destined to the mitochondrial matrix, while proteins to be inserted into the inner mitochondrial membrane contain an internal presequence-like signal (reviewed in Schleiff and Becker, 2011).

Upon in silico analysis of the 47 nuclear encoded proteins using TargetP (Emmanuelsson et al., 2000), 29 proteins are predicted to comprise a cleavable mitochondrial presequence (data not shown). However, presequence definition by TargetP was reported to be largely incorrect if applied to mitochondrial proteins from plants (error rate of 70\%, Huang et al., 2009). In another approach to define the presequences of complex I subunits, we determined the apparent molecular masses of all 47 nuclear encoded subunits of Arabidopsis by use of 2D Blue native / SDS PAGE (as displayed at the 
GelMap portal www.gelmap.de) and compared them with their calculated molecular masses (Supp. table 3). Since most plant mitochondrial presequences comprise 20-70 amino acids (Zhang and Glaser, 2001), which corresponds to about 2-8 kDa in mass, we defined the presence of a mitochondrial presequence if the apparent molecular mass of a complex I subunit was reduced by at least $2 \mathrm{kDa}$ in relation to its calculated molecular mass. Using this criterion, 12 of the 47 nuclear encoded complex I proteins comprise a cleavable presequence (Supp. table 3). Interestingly, only 3 of the 28 nuclear encoded proteins of the membrane arm seem to possess a presequence (10\%), while 9 of the 19 proteins constituting the peripheral arm or the carbonic anhydrase domain are equipped with one (50\%). However, one has to keep in mind that although the gel-based protein size determination already gives some good indication on the actual size of the mature complex I proteins, we cannot rule out that some of the proteins analyzed here are processed or modified at other positions than the $\mathrm{N}$-terminus and thus an experimental validation of their presequences is still needed. Indeed, $\mathrm{N}$-terminal sequences of complex I subunits from either Arabidopsis, rice or potato have already been experimentally defined by mass spectrometry or Edman degradation for overall 16 subunits: the B13 subunit (Kruft et al., 2001), the B14, B14.5, B18, B22, CAL1, CAL2, 18 kDa, 75 $\mathrm{kDa}$, PSST and TYKY subunits (Huang et al., 2009), the CA1, CA2 and CA3 subunits (Klodmann et al., 2010) and the AGGG and B12 subunits (Salvato et al. 2014) (Supp. table 3). Nine of these subunits lack a cleavable presequence, while seven comprise one. In 14 of 16 cases (88\%), these results are in line with our GelMap-based prediction (Supp. table 3).

Analyses of experimentally defined presequences of complex I subunits in Arabidopsis (5 proteins) rice (7 proteins) reveals the following properties (Supp. table 4): (i) presequence length varies between 11 amino acids (B13 subunit of Arabidopsis) and 46 amino acids (PSST subunit of Arabidopsis); (ii) amino acid composition of the presequences is much enriched in alanine (21\%), arginine (15\%), leucine (14\%) and serine (12\%); (iii) presequences completely lack glutamate and aspartate; (iv) the presequences have a disposition to form amphiphilic $\alpha$-helices and ( $v$ ) an arginine residue is located at position -2 or -3 with respect to the cleavage site in nearly all presequences of complex I subunits. These presequence properties are in line with the general properties defined for mitochondrial presequences in plants (Zhang and Glaser, 2001). The arginine at position $-2 /-3$ is known to be a prerequisite for presequence cleavage by the mitochondrial processing peptidase. Due to the very limited number of defined presequences for complex I subunits in plants, it currently cannot be determined whether complex I subunits share common presequence properties which significantly differ from the properties of presequences of other mitochondrial proteins not forming part of complex I.

We conclude that more than half of the complex I subunits and nearly all of the subunits of its membrane arm seem to lack a cleavable presequence in plants. These proteins might contain internal presequence-like signals which are difficult to detect. Hence, more experimental evidence is needed to dissect the import pathways of complex I subunits into plant mitochondria, which will be crucial for the understanding of the sophisticated assembly of this protein complex. 


\subsection{Assembly, assembly factors}

\section{Assembly of complex I}

To date, the assembly of complex I has been mainly studied in fungi and mammals. Complex I is assembled in a modular way in which building blocks, each containing a few subunits, are joined together to establish a functional complex I (Mimaki et al., 2012; Vogel et al., 2007b). These building blocks have been identified in mutants lacking a subunit (Antonicka et al., 2003; Nehls et al., 1992) or by following the insertion of labelled subunits into the growing complex (Lazarou et al., 2007; Ugalde et al., 2004; Vogel et al., 2007a). Compared with mammals, considerably fewer complex I mutations have been studied in plants and little data on complex I assembly is available. Nevertheless, a similar modular assembly pathway has been suggested (Vogel et al., 2007b). Recently, several Arabidopsis mutants each lacking a different subunit have been investigated for accumulating assembly intermediates, and a first model for the assembly of the membrane arm of complex I in plants was proposed (Meyer et al., 2011). This work showed that in plants, like in all other organisms studied to date, the assembly of the membrane arm involves joining together of an intermediate containing ND1 with an intermediate containing ND2, followed by the addition of a module containing ND4 and ND5. In addition, the study highlighted a major difference between the plant and mammalian pathways: the plant-specific subunit CA2 is essential for the initial step of the membrane arm assembly (Meyer et al., 2011). Two of the intermediates described by Meyer et al. (2011) have been identified as having a higher turnover than complex I, confirming these intermediates as assembly subcomplexes (Li et al., 2013). In addition, import of several plant-specific subunits into isolated mitochondria lead to their rapid incorporation in complexes with sizes in accordance with the membrane arm intermediates (Carrie et al., 2010; Li et al., 2013). On the other hand, no assembly intermediates of the peripheral arm have so far been detected in plants. Hence, the joining of the matrix and membrane arms in plant mitochondria has not yet been elucidated. Additional work involving the analysis of new mutants and the utilization of alternative strategies, such as the labelling techniques recently developed in the plant system (Li et al., 2013), will be required to better characterize the complex I assembly pathway in plants.

\section{Assembly factors}

Analyses of molecular defects responsible for complex I deficiency in human mitochondria defined three classes of mutations: mutations in complex I subunits, mutations in proteins involved in mitochondrial gene expression and mutations in assembly factors (Hoefs et al., 2012). Assembly factors are proteins essential for the assembly of complex I which are absent from the mature complex. Proteins involved in mitochondrial protein import or mitochondrial gene expression are not considered assembly factors. Assembly factors are often associated with assembly intermediates which they stabilize thus aiding the progress of assembly. In mammals, several such factors have been identified (for review see (Mimaki et al., 2012; Pagniez-Mammeri et al., 2012). Orthologs of different mammalian assembly factors are also present in the Arabidopsis genome (E.H. Meyer, unpublished data), however, the potential roles of these candidates in complex I assembly are yet to be investigated. To date, only one potential plant complex I assembly factor has been described in the model organism $A$. thaliana. This factor is the last enzyme of the ascorbate biosynthesis pathway, the L-galactono-1,4-lactone dehydrogenase (GLDH). GLDH is absent from mature complex I but has been shown to be associated with a smaller version of the complex (Heazlewood et al., 2003) and with smaller complexes likely representing complex I assembly intermediates (Schertl et al., 2012). As 
the knock-out mutant of GLDH does not accumulate complex I (Pineau et al., 2008), GLDH can be considered the first complex I assembly factor described for plants. The role of GLDH during complex I assembly remains to be resolved. Given that complex I assembly in plants differs from the mammalian pathway, further plant-specific assembly factors might be involved. The determination of the composition of previously identified assembly intermediates will almost certainly identify new candidate assembly factors in plants.

\subsection{Architecture and internal subunit arrangement}

Proteome projects have been carried out to systematically investigate the subunit composition of complex I in plants (Cardol et al., 2004; Heazlewood et al., 2003; Klodmann and Braun, 2011; Klodmann et al., 2010; Li et al., 2013; Meyer et al., 2008; Peters et al., 2013; Sunderhaus et al., 2006). According to the most recent investigation, complex I of the model plant Arabidopsis thaliana consists of at least 49 types of subunits (Peters et al., 2013, Supp. table 1). As mentioned above, 40 of these subunits are present as homologs in complex I particles of bovine mitochondria. The remaining nine subunits are considered to be special constituents of mitochondrial complex I in plants. Seven of the 49 subunits occur in pairs of isoforms in Arabidopsis. Therefore, overall 56 genes encode complex I proteins in Arabidopsis, nine of which are localized on the mitochondrial genome and 47 on the nuclear genome. This number may even rise further in the future because additional proteins were identified representing potential complex I subunits (Peters et al., 2013, Supp table 2).

Electron microscopy analyses revealed that plant complex I has a unique structure which includes an additional domain (Figure 2). This domain has a spherical shape and is attached to the membrane arm at a central position on its matrix exposed side (Dudkina et al., 2005). It also has been described for complex I of potato, maize, and the alga Polytomella (Bultema et al., 2009; Peters et al., 2008; Sunderhaus et al., 2006). The domain includes a set of subunits which occur in plants as well as in some protist lineages and which resemble gamma-type carbonic anhydrases (Perales et al., 2004; Gawryluk and Gray, 2010). Three of these proteins have a conserved active site and are termed carbonic anhydrase 1, 2 and 3 (CA1, CA2 and CA3) while the other two proteins show less similarity and are designated "carbonic anhydrase-like" proteins 1 and 2 (CAL1 and CAL2) (Perales et al., 2004, 2005). As mentioned above another plant specific protein associated with complex I is the Lgalactono-1,4-lactone dehydrogenase which catalyzes the terminal step of ascorbic acid biosynthesis. It most likely does not form part of mature complex I but evidence has been presented that it aids assembly of complex I in plants (Pineau et al., 2008; Schertl et al., 2012). Some further plant specific complex I subunits have low molecular masses and are of unknown function.

To facilitate complex I research in plants, two 2D gel-based reference maps were recently generated which are freely accessible via the GelMap portal (http://www.gelmap.de; Senkler and Braun, 2012). Information on all identified complex I spots is retrievable from interactive spot maps. One of the maps has been constructed from the dis-assembled complex I of Arabidopsis (http://www.gelmap.de/complex-i/). On the basis of a systematic analysis of the protein compositions of defined complex I subcomplexes a rough internal architecture of complex I has been resolved (Klodmann et al., 2010). The second map (http://www.gelmap.de/arabidopsis-3d-complexi/) visualizes complex I subunits upon separation by three dimensional BN / SDS / SDS PAGE (Peters et al., 2013). Besides subunit ND4L it includes a complete set of currently known complex I subunits 
in Arabidopsis. Figure 3 summarizes the current knowledge on the internal subunit arrangement of complex I in plants.

\section{Function and Regulation (Adulthood/Maturity)}

Biosynthesis and assembly of functional complex I follow a long route and include several complicated and energy-costly biochemical processes. What is the cellular benefit for all this major investment? What is the physiological role of mitochondrial complex I, especially in the context of photosynthesis, in the plant cell? The following sections summarize its activities, its physiological roles, its partners and its integration into metabolic networks.

\subsection{Physiological roles of complex I}

\section{Oxidoreductase and proton translocation functions}

The crystal structure of the bacterial complex I has provided first insights into the coupling mechanism of oxidoreduction and proton translocation. NADH is oxidized by a flavine mononucleotide (FMN) attached to the $51 \mathrm{kDa}$ subunit (Figure 1). A chain of seven iron-sulphur (FeS) clusters coordinated by subunits of the $\mathrm{N}$ - and $\mathrm{Q}$ modules passes electrons from the $51 \mathrm{kDa}$ subunit to PSST. The latter subunit includes FeS cluster N2 which transfers the electrons to quinone. This takes place at a quinone binding pocket close to the interface between the two arms of complex I. Another FeS cluster, N1a, is located in close proximity to FMN. As NADH transfers two electrons to complex I but only one electron can be forwarded by FMN, the cluster N1a keeps one electron until the first has passed through the chain. Hence, FMN in complex I is also called "two-to-one electron converter" (Brandt, 2006). Reduction of ubiquinone triggers an electrostatic chain reaction in the membrane arm which drives proton translocation across the bacterial or mitochondrial membrane. Based on the bacterial crystal structure the following mechanism has been proposed (Baradaran et al., 2013): upon quinone reduction (conversion of quinone to quinol), four proton half channels formed by ND2, ND4, ND5 and ND3/6/4L simultaneously open at the matrix side of the membrane arm. Protons then bind to charged amino acid residues in the center of the inner mitochondrial membrane. Upon exchange of the quinol by quinone, the four half channels close and four half channels on the other side of the inner mitochondrial membrane open, allowing the four protons to be released into the mitochondrial intermembrane space. As a consequence, the four protons are translocated across the inner mitochondrial membrane per oxidized NADH. Due to the similarities in the basic structure of complex I across different lineages, this reaction mechanism can also be anticipated for complex I of plants.

\section{Role of complex I function in respiration and photorespiration}

The respiratory chain is estimated to translocate 10 protons from the mitochondrial matrix to the mitochondrial intermembrane space per oxidized NADH (Watt et al., 2010). Four of these protons are translocated by complex I. Re-entry of three protons from the mitochondrial intermembrane space into the mitochondrial matrix at the ATP synthase complex is necessary to synthesize one molecule of ATP (Rich, 2003). Consequently, complex I makes a major contribution to oxidative phosphorylation. However, mitochondria of plants also contain alternative NAD(P)H dehydrogenases (Rasmusson et al., 2004; Millar et al., 2011). Genes encoding these enzymes are light-regulated and 
contribute to NADH oxidation at daytime. The necessity to increase NADH oxidation capacity in plants at daytime is a consequence of photosynthesis. In most plants, photosynthesis is coupled to photorespiration which includes glycine-serine conversion in mitochondria. The decarboxylation of glycine is linked to $\mathrm{NAD}^{+}$reduction and generates additional NADH with high rate, which requires efficient re-oxidation by mitochondrial NADH dehydrogenases. However, deletion of complex I by knocking-out a gene encoding one of its subunits is not always lethal. Hence, most likely due to the presence of the alternative $\mathrm{NAD}(\mathrm{P}) \mathrm{H}$ oxidoreductases, plants have a particularly flexible OXPHOS system.

\section{Role of complex I function in photosynthesis}

Indication that complex I plays an important role in photosynthesis comes from various experimental findings. First, complex I is more abundant in green tissues than in non-green tissues. This has been shown by comparing the mitochondrial proteome in roots and shoots (Lee et al., 2011) but also by estimating the relative abundance and activities of respiratory complexes in different tissues (Peters et al., 2012). Furthermore, characterization of mutants has revealed clear effects of down-regulation or deletion of complex I on photosynthesis (Noctor et al., 2004). While the capacity of the photosynthetic apparatus does not seem to be affected by the reduced complex I activity (Dutilleul et al., 2003b; Meyer et al., 2009), the photosynthetic activity measured as the efficiency of photosystem II or as chloroplastic electron transfer is reduced (Juszczuk et al., 2007; Meyer et al., 2009; Sabar et al., 2000). This reduction of photosynthetic activity is more pronounced under high light conditions or under conditions that favor photorespiration, suggesting that complex I is playing a particularly important role for this metabolic pathway (Dutilleul et al., 2003b) (see above). As a consequence, the growth phenotype and the lower photosynthetic activity of complex I mutants can be overcome when plants are grown under high $\mathrm{CO}_{2}$ conditions to prevent photorespiration (Priault et al., 2006). Therefore the reduced photosynthetic activity of complex I mutants could be explained by limited $\mathrm{CO}_{2}$ supply for photosynthesis. Alternatively, it may be caused by a change in cellular redox homeostasis. Indeed, under high light or photorespiratory conditions, an over-reduction of the plant cell is expected to happen (increased $\mathrm{NAD}(\mathrm{P}) \mathrm{H} / \mathrm{NAD}(\mathrm{P})^{+}$ratio). In the context of a complex I mutation, the total NADH concentration and the $\mathrm{NAD}(\mathrm{P}) \mathrm{H} / \mathrm{NAD}(\mathrm{P})^{+}$ratio are increased (Hager et al., 2010). These observations suggest that in addition to its role in oxidative phosphorylation, the respiratory chain plays a key role in maintaining the redox system of the plant cell in a balance. Complex I, together with the alternative $\mathrm{NAD}(\mathrm{P}) \mathrm{H}$ dehydrogenases, probably forms part in this overreduction protection mechanism by controlling cellular NADH concentrations. Another interaction between respiratory chain and photosynthesis has been evidenced in Chlamydomonas reinhardtii: the activity of the cytochrome pathway controls the expression of photosynthetic genes (Matsuo and Obokata, 2006). Similar regulation may occur in land plants as transcripts encoding the light reaction of photosynthesis are significantly down-regulated in complex I mutants (Meyer et al., 2009; Pellny et al., 2008). In summary, the extensive characterization of complex I mutants indicates that there are several potential levels for the control of photosynthesis by complex I but the mechanisms involved remain unknown. However, findings on complex I mutants at the same time have to be taken with caution because in general it is difficult to discriminate between direct complex I effects and indirect effects caused by modified primary metabolism. Understanding complex I function in green tissues is essential to unravel the interactions between mitochondria and chloroplasts. 


\section{Carbonic anhydrase function}

The physiological role of the five CA/CAL subunits present in Arabidopsis complex I remains elusive. Based on several indirect experimental findings, $\mathrm{CO}_{2}$-bicarbonate conversion at complex I was proposed to be part of a $\mathrm{CO}_{2}$ transport mechanism between mitochondria and chloroplasts (Braun and Zabaleta, 2007; Zabaleta et al., 2012). The proposed mechanism resembles the cyanobacterial carbon-concentration mechanism (CCM). Furthermore, it has been suggested that complex I might represent a bicarbonate translocase in the context of the proposed transport system (Zabaleta et al., 2012). Besides their proposed role for carbon fixation, the CA/CAL subunits are essential for assembly of plant complex I (Perales et al., 2005; Meyer et al., 2011; Li et al., 2013).

\section{Other functions}

Complex I includes several subunits resembling proteins of known function which exhibit activities in the context of other biochemical processes. For instance, subunits resembling proteins of the preprotein translocase of the inner mitochondrial membrane (the TIM complex) form part of complex I (Klodmann et al., 2011; Wang et al., 2012b). The B16.6 subunit resembles the GRIM19 protein which participates in an apoptotic signal transduction pathway (Remacle et al., 2008). Finally, complex I in fungi and mammals includes an acyl carrier protein and it has been shown that fatty acid biosynthesis can take place at the surface of fungal complex I (Zensen et al., 1992). However, this subunit is not present in complex I from plants (Meyer et al., 2007).

In summary, complex I is not only an oxidoreductase but rather should be considered a multifunctional platform that hosts a range of biochemical processes (Figure 4). Future research will need to explore how exactly the different functions of complex I are interconnected.

\subsection{Posttranslational modifications}

Since complex I is a major pacemaker of oxidative phosphorylation and a hotspot for mitochondrial reactive oxygen species (ROS) production (see section 3.4.), it can be expected that its activity is regulated in response to cellular demand for oxidation of NADH generated from respiratory and photorespiratory substrates. Both transcriptional and posttranscriptional regulatory mechanisms could play a role in the regulation of complex I activity. However, in contrast to the mitochondrial alternative dehydrogenase transcripts, most of the nuclear-encoded complex I transcripts are only mildly regulated in dependence on abiotic and biotic stresses (reviewed in Schwarzländer and Finkemeier, 2013). Furthermore, most of the complex I subunits have been estimated to have a relatively slow protein turnover [see below and (Nelson et al., 2013)]. Hence, posttranslational modifications would be an efficient means to promptly regulate complex I activities as required by cellular metabolism. Nevertheless not many plant mitochondrial proteins have been found to carry post-translational modifications thus far (Hartl and Finkemeier, 2012).

\section{Phosphorylation}

None of the complex I subunits have been identified in any of two different targeted phosphoproteomic approaches on isolated mitochondria of Arabidopsis cell cultures or potato tubers (Bykova et al., 2003; Ito et al., 2009). The lack of identified phosphorylated complex I subunits in these two studies, however, could be due to the loss of phosphorylation during the long 
mitochondrial isolation procedures rather than to the actual lack of complex I phosphorylation in plants. Indeed, in three different shotgun phosphoproteomic approaches of whole Arabidopsis protein extracts, 11 phosphosites on either serine, threonine or tyrosine residues have been identified on 9 different complex I subunits (Suppl. table 5; Heazlewood et al., 2008; Reiland et al., 2009; Reiland et al., 2011; Engelsberger and Schulze, 2012). Seven of these proteins (24kDa, 51kDa, $75 \mathrm{kDa}$, PGIV, B13, CAL1, CAL2) are protruding into the mitochondrial matrix, while the other two are more integral to the membrane arm according to the latest complex I model for plants (Figure 3). Hence, the complex I subunits which are facing the matrix side are potential targets of one of the 10 protein kinases identified in the Arabidopsis mitochondrial proteome (Heazlewood et al., 2004). Intriguingly more than half of the identified proteins are phosphorylated at tyrosine residues. Tyrosine (Tyr) phosphorylation of mitochondrial proteins was previously shown to be tightly connected to the mitochondrial redox state and thus could have an important regulatory role in the regulation of the electron transport chain (Håkansson and Allen, 1995; Salvi et al., 2005).

Furthermore, in mammalian mitochondria Tyr phosphorylation of respiratory complexes was shown to be of great importance for the regulation of respiration (reviewed in Cesaro and Salvi, 2010). Recently, it was demonstrated that phosphorylation of Tyr193 of NDUFV2, the human homolog to the Arabidopsis 24kDa subunit, is a requirement for complex I activity in T98G cells (Ogura et al., 2012). Serine and threonine phosphorylation have also been shown to be important for the regulation of complex I activity in mammalian mitochondria. The CAMP-dependent phosphorylation of NDUFS4 (18kDa subunit), for example, enhances the import of this subunit into mitochondria in human fibroblasts. This was shown to be important for the exchange of the oxidatively damaged subunit with the de novo synthesized subunits in the mature complex (De Rasmo et al., 2012). Oxidatively damaged complex I subunits were also detected in mitochondria isolated from potato tubers (Møller and Kristensen, 2006), and thus it remains to be explored whether similar phosphorylation-dependent repair mechanisms do exist in plant mitochondria.

\section{Thiol-related posttranslational modifications}

Several subunits of complex I contain cysteine residues that may act as targets of oxidative thiol modification. Using protein extracts of different plant species, trapping experiments have identified most subunits of the peripheral arm (including the $24 \mathrm{kDa}, 75 \mathrm{kDa}, 30 \mathrm{kDa}, 49 \mathrm{kDa}, \mathrm{B} 13$ and TYKY -1 subunits), as well as some of the membrane arm (including B22, PDSW-2, MNLL) as potential targets of glutaredoxins and thioredoxins (Balmer et al., 2004; Rouhier et al., 2005; Yoshida et al., 2013). This suggests that several thiols are available for redox-modification in principle. If those cysteines are also sterically available on the surface of the intact complex, if their modification can occur under in vivo redox conditions and what mechanistic impact that may have on complex I is currently unclear, however. Also the nature of modification remains unclear, with protein-protein disulfide formation, glutathionylation and S-nitrosation as good candidates. While mammalian complex I can be Snitrosated as well as S-glutathionylated, analogous information is currently still lacking for plants (Dahm et al., 2006; Palmieri et al., 2010, Kang et al., 2012). S-glutathionylation was shown to occur even under mild oxidative stress and correlated with an inactivation of complex I (Hurd et al., 2008). Only recently glutathionylation of the conserved Cys-226 of the $75 \mathrm{kDa}$ subunit was identified as primary mechanism for complex I inactivation, which occurs upon depletion of reduced glutathione (Kang et al., 2012). Of particular interest for regulation of complex I activity is a cysteine in the mitochondrial encoded ND3 subunit of the complex I membrane arm, that is highly conserved in eukaryotes, including plants. This thiol (Cys-39 and Cys-45 in bovine and plant ND3, respectively) is 
located in a matrix loop adjacent to the peripheral arm (Galkin et al., 2008). For mammals the cysteine has been shown to be available to S-nitrosation in the inactive state of complex I only (Galkin et al., 2008; Galkin and Moncada, 2007). The active/inactive (A/D) transition is a well conserved feature of complex I in eukaryotes and provides a potential regulatory switch for complex I activity (Vinogradov, 1998). For plants a similar transition is expected, but remains to be characterized in detail (indications for two different functional states of complex I in plants indeed come from early biochemical work on matrix NADH oxidation, Moller and Palmer, 1982; Soole et al. 1990). The inactive state is favored by lack of substrate and hypoxia both in vitro and in vivo (Galkin et al., 2009). Instead of dehydrogenase activity the inactive state of complex I can mediate $\mathrm{H}^{+} / \mathrm{Na}^{+}$ exchange (Roberts and Hirst, 2012). The transition back to the active state can be triggered by resupply of substrate or oxygen, but is inhibited by S-nitrosation of the ND3 cysteine (Galkin et al., 2009). S-nitrosation of ND3 is of particular importance during reperfusion of ischemic tissue to prevent ROS production and damage to complex I. This thiol switching mechanism has recently been shown to operate in vivo were it can mediate cardioprotection (Chouchani et al., 2013). Similar principles could also help keeping complex I inactive during assembly or repair. The S-nitrosation of ND3 is fully reversible and can be removed by glutathione and thioredoxin to reactivate complex I (Chouchani et al., 2013). That makes redox modification of this critical cysteine an intriguing potential target for redox dependent regulation of complex I activity in response to changing physiological conditions. Such level of regulation is particularly interesting in plants, where the requirement for reduction of matrix NADH may vary strongly between light and dark, and where alternative dehydrogenases need to work in concert with complex I.

\section{Lysine acetylation}

The reversible acetylation of lysine residues was recently shown to be of major importance for the regulation of mitochondrial functions (Masri et al., 2013), including the regulation of complex I activities in mouse mitochondria (Ahn et al., 2008). Similar to protein phosphorylation, lysine acetylation is fully reversible and regulated by the antagonistic action of lysine acetyltransferases and deacetylases. Although not much is known yet about the identity of mitochondrial acetyltransferases, lysine deacetylation in mitochondria of plants and animals is regulated by sirtuintype proteins (reviewed in Sauve, 2010; König et al., 2014). Sirtuins (Sirt) are of great interest with regard to the regulation of metabolism as their activity is dependent on $\mathrm{NAD}^{+}$and usually increases during starvation. Mice with deficiency in Sirt3 showed decreased complex I activity due to increased acetylation of the complex I subunit NDUFA9 (39kDa) (Ahn et al., 2008). Recently several additional lysine acetylation sites on complex I subunits NDUFB3 (B12), NDUFB11 (ESSS), NDUFS7 (PSST) and NDUFS8 (TYKY) were identified and showed an increase in acetylation in Sirt3-deficient mice or human cell lines (Sol et al., 2012; Rardin et al., 2013). However, the functional relevance of each individual site has not yet been investigated in detail. Lysine acetylation can also be detected by Western-blot analysis on complex I subunits in Arabidopsis, albeit the identity of the actual lysine acetylation sites have not been confirmed by mass spectrometry thus far (Finkemeier et al., 2011; Wu et al., 2011; I. Finkemeier and A. König, unpublished results). Hence, it remains to be determined whether lysine acetylation is also an important regulatory mechanism for complex I activity in plants. 


\subsection{Protein and lipid interactions of complex I}

Apart from its enzymatic substrates ( $\mathrm{NADH}$, ubiquinone, and, (potentially) $\mathrm{CO}_{2}$ for the CAs and CALs), complex I also interacts with other molecules such as proteins and lipids. Proteins associate with complex I either in their monomeric forms or in the form of protein complexes. Being a membranelocalized enzyme, complex I also interacts with lipids, some of which have the potential to influence its interactions with other proteins. Since data on plant complex I interactions is scarce, data from phylogenetically distant species are also presented here and discussed in terms of their validity for plants.

\section{Protein interactions}

Complex I is well known for its association with the dimeric cytochrome c reductase complex (complex $\mathrm{II}_{2}$ ) and the resulting formation of a respiratory supercomplex in bacteria, mammals and plants (Dudkina et al., 2005; Eubel et al., 2003; Schägger et al., 2002). Given that plant complex $\mathrm{III}_{2}$ also associates with the cytochrome c oxidase (complex IV, Eubel et al., 2004; Krause et al., 2004), it indirectly connects complex IV to complex I as well. Stoichiometric associations of these three complexes are referred to as respirasomes (Schägger and Pfeiffer, 2000) since, in the presence of the mobile electron carriers ubiquinone and cytochrome $c$, they are capable of transferring electrons from NADH all the way to molecular oxygen. Moreover, even higher organizations of respiratory complexes (including complex I) have been suggested on the basis of electron microscopy and bluenative (BN) PAGE analyses (Allen et al., 1989; Bultema et al., 2009; Wittig et al., 2006).

Upon solubilization of plant mitochondria with the non-ionic detergent digitonin, the supercomplex consisting of complexes I and $\mathrm{III}_{2}$ (termed ' $\mathrm{SC} \mathrm{I/III}$ ' in the following) is the most prominent supercomplex on BN gels. Complex IV containing supercomplexes either are not strong enough to survive solubilization quantitatively or do not play major roles in respiratory electron transfer. In any case, the physiological benefits inherent to the interaction of complexes I and III are speculative and remain the subject of ongoing discussion. Amongst others, they include regulation of electron flow through the branched plant mitochondrial chain, reduction in the generation of reactive oxygen species (ROS) and an increased capacity of the cristae membranes to accommodate proteins (Dudkina et al., 2005, 2010). Apart from the latter, most of these processes rely heavily on substrate channeling i.e. the rapid sequestration of reaction products within the complex. However, true substrate channeling within $\mathrm{pSC} \mathrm{I} / \mathrm{III}_{2}$ would require the presence of two separate ubiquinone pools within the inner mitochondrial membrane. The first pool would be free to accept electrons from complex I monomers, the alternative NADH dehydrogenases, complex II, and other enzymes feeding electrons into the respiratory chain. In addition, the second, independent pool of ubiquinone would be incorporated into the $\mathrm{SC} \mathrm{I} / \mathrm{III}_{2}$ and only uses the electrons delivered from complex I within the supercomplex. Current data do not explicitly contradict the notion of two separate pools but evidence in favor of their existence is also lacking. The most profound argument against the existence of substrate channeling with $\mathrm{pSC} \mathrm{I} / \mathrm{III}_{2}$ is the location of the ubiquinone binding site within complex I. Structural data on $T$. thermophilus complex I locate it at the end of a cavity on the far side of the contact area with complex III. In addition, the entrance of this cavity is also pointing away from the cytochrome $c$ reductase (Baradaran et al., 2013), resulting in the longest possible diffusion path for ubiquinone within the complex. In the light of these findings, substrate channeling cannot be considered as the most likely explanation for $\mathrm{SC} / / \mathrm{III}_{2}$ formation. However, compared to evenlydistributed singular respiratory complexes the close proximity of complexes I and $\mathrm{III}_{2}$ will allow for 
faster electron transfer due to reduced diffusion distances. Therefore, the association of complex I with other members of the respiratory chain is expected to have an impact on mitochondrial electron transfer even in the absence of true substrate channeling.

Apart from complex $\mathrm{II}_{2}$, recent analysis of members of the Preprotein and Amino acid Transporter (PrAT) family revealed the presence of two of its members in respiratory complex I as well as in the preprotein translocase of the inner mitochondrial membrane, the TIM17/23 protein complex (Wang et al., 2012b). Overexpression of one of these proteins (TIM23-2) leads to reduced complex I abundance. By contrast, knock-out mutants of complex I subunits or proteins which affect assembly of the protein complex are characterized by increased levels of TIM23-2. Interestingly, plants overexpressing TIM23-2 also phenocopy complex I knock-out plants, suggesting functional interaction between these protein complexes. It remains to be seen if this also includes physical association of the two complexes. For baker's yeast (lacking complex I) physical interactions between protein import components and respiratory protein complexes have been reported (van der Laan et al., 2006).

In addition to protein complexes and excluding assembly factors, also individual proteins were found to interact with complex I or its subunits. In vitro binding assays of purified pig heart complex I with matrix NAD-coupled dehydrogenases (Sumegi and Srere, 1984) suggested interactions between these enzymes but similar data on plant complex I are missing. However, using the list of complex I subunits as shown in Supp. table 1 to query the Arabidopsis subcellular database (SUBA, queried 17.06.2013; Tanz et al., 2013) yielded a broad spectrum of potential complex interacting proteins. The subcellular localizations of these proteins are diverse and, after subtracting other complex I subunits, only those proteins unambiguously assigned to mitochondria are considered here.

The most prominent group among these proteins is composed of members of the prohibitin family (Atphb1, At4g28510; Atphb2, At1g03860, Atphb3, At5g40770; Atphb4, At3g27280; Atphb6, At2g20530; Atphb7, At5g44140). The reported interactions between prohibitins and complex I are inferred from 3D BN/dSDS gels (Meyer et al., 2008). Since the prohibitin complex runs close to complex I in the first dimension BN-PAGE, it is most likely that the presence of prohibitins within the complex I dSDS gel is not due to physical association of the two complexes but rather due to the presence of small amounts of the prohibitin complex during the excision of the complex I band from the BN-PAGE. Prohibitins therefore cannot be considered bona fide complex I interactors.

Using a yeast two-hybrid $(\mathrm{Y} 2 \mathrm{H}$ ) approach, the majority (five) of the remaining six proteins was found to interact with the $\gamma$-type carbonic anhydrase 3 (At5g66510) while a single protein interacts with a member of the LYR family of Fe/S cluster biogenesis protein (At4g34700, Arabidopsis Interactome Mapping Consortium, 2011). This group of complex I interacting proteins spans a wide functional range and includes a $2 \mathrm{Fe}-2 \mathrm{~S}$ ferredoxin (At3g07480), a protein involved in the assembly of iron-sulfur clusters destined to remain in mitochondria or to be exported to the cytosol (Nfu4, At3g20970, Leon et al., 2003), a small heat-shock protein (At4g25200), a co-chaperone (At5g55200) as well as a putative thiol-disulphide oxidoreductase (At5g50100) and a tetratricopeptide repeat protein (At5g09450). However, the high percentage of non-mitochondrial interactors found by the $\mathrm{Y} 2 \mathrm{H}$ approach implies the presence of a considerable percentage of false positively identified proteins among the data set of putative complex I interacting proteins. It is also worth mentioning that these data do not allow discrimination between interactions with individual or interfaces of complex I as a whole. Their physical connection with complex I function therefore remains unclear. Interestingly, no 
complex III subunits are among the potential interactors although the interaction between the two complexes is stable enough to withstand solubilization and electrophoresis. Several reasons for the lack of those established interactions seem feasible. First, complex I and complex III subunits are part of large $(0.5-1.0 \mathrm{MDa})$ complexes and for the majority of the theoretically calculable interactions between the subunits of the complexes distances between the two complexes may simply be too long in order to trigger a response. Moreover, large reporter groups on subunits may prevent their integration into the complexes, which would prevent a signal even if those subunits sit in close proximity within the supercomplex. However, such a scenario would also prevent signals from associations of subunits within the same complex, which have clearly been picked up by the approach. An additional reason for the lack of complex I/ complex III interactions with the $\mathrm{Y} 2 \mathrm{H}$ method might be due to the presence of other molecules within the supercomplex structure preventing immediate contact of the subunits of one complex with those of the other. Such molecules may, for example, be lipids.

\section{Lipid interactions}

Mitochondrial protein complexes not only depend on the provision of protein subunits for proper function but also require the presence of phospholipids (Fleischer et al., 1962). Most of these lipids are easily detachable following treatment with organic solvents or detergents and have no or little influence on the activity of the enzymes. By contrast, the dimeric phospholipid cardiolipin (CL) behaves differently in requiring more stringent conditions for its removal from mitochondrial protein complexes. Within mammalian cells appreciable amounts of $\mathrm{CL}$ are only present in the mitochondrial membrane systems, with the bulk of it located in the inner membrane (Gebert et al., 2009). While in most cases $\mathrm{CL}$ is not essential for the function of mitochondrial protein complexes, their respective performances are markedly increased in the presence of $\mathrm{CL}$ (for a review on cardiolipin interaction with mitochondrial proteins and protein complexes see Schlame et al., 2000). For complex I isolated from beef heart mitochondria Fry and Green (1981) demonstrated that it contains tightly bound CL and that its removal from the complex is accompanied by a loss of function. No interaction of cardiolipin with plant complex I has yet been reported. However, plants are capable of synthesizing $\mathrm{CL}$ and the last enzyme in the pathway of its synthesis, $\mathrm{CL}$ synthase, is located in the mitochondria of plants (Katayama et al., 2004). From this and the data on mammalian complex I it may be predicted that $\mathrm{CL}$ is also part of plant respiratory chain complexes, including complex I.

Apart from being an integral part of individual inner membrane protein complexes, cardiolipin also promotes formation of respiratory supercomplexes. While the integrity of respiratory complexes II, III, and IV (baker's yeast does not possess complex I) in cardiolipin deficient yeast remains unchanged, the abundances of complex III and complex IV containing supercomplexes is reduced (Zhang et al., 2005). Disturbances in acyl chain remodeling of $\mathrm{CL}$ in Barth syndrome patients mainly affect complex III : IV interactions but, to a lesser extent, also those between complexes I and III (McKenzie et al., 2006). Cardiolipin is therefore either involved in the formation of such supercomplexes or in maintaining their stability. In either case, as a result, the respiratory capacity of $\mathrm{CL}$ deficient mitochondria is markedly reduced. Similar to the role of cardiolipin in individual mitochondrial complexes, little is known about the utilization of cardiolipin for plant mitochondrial supercomplexes. The common ancestral origin and the elementary similarities between the plant, yeast and mammalian respiratory chain strongly suggest that $\mathrm{CL}$ is likely to also have an impact on the respiratory supercomplexes in plants. Arabidopsis knock-out mutant lines for CL synthase are 
now available and recently gave first insights into the role of $\mathrm{CL}$ in plant respiratory electron transport (Katayama and Wada, 2012; Pineau et al., 2013).

\subsection{ROS formation at complex I}

Complex I is a major contributor towards mitochondrial ROS production. This assumption is largely based on results from isolated mammalian mitochondria and has been extrapolated to plants. While this leap appears justified based on overall conservation of complex I structure and function, it exemplifies a more general shortage of rigorous ROS measurements in plant mitochondria. Due to the specialized role of complex I in respect to photosynthesis plant specific modes of mitochondrial ROS generation remain a possibility and deserve specific research attention.

In mammalian mitochondria the NADH binding site within the $51 \mathrm{kDa}$ subunit of complex I can generate superoxide by a single electron reduction step from reduced flavin mononucleotide (FMN) to molecular oxygen. That site is structurally and functionally conserved between mammals and plants, which implies similar properties in superoxide production. Oxygen reduction by single electron transfer is thermodynamically and kinetically possible due first to a steric accessibility of FMN for oxygen and secondly to a highly negative redox potential of the FMN redox couple. While the first possibility follows from the requirement of the site to accommodate NADH as substrate, the second depends on the bioenergetic situation and there are two extreme scenarios under which high rates of superoxide generation can occur (reviewed by (Murphy, 2009)). On the one hand, a high $\mathrm{NADH} / \mathrm{NAD}^{+}$ratio in the matrix leads to overreduction, an extended lifetime and a more negative redox potential of the reduced FMN site. Inhibition of the electron transport chain can contribute to this mode, by causing electrons to back up. On the other hand, when a highly reduced ubiquinone pool (due to sources of electrons other than NADH) coincides with a high proton motive force, superoxide can be produced at complex I by 'reverse electron transport' (Lambert and Brand, 2004). Under such conditions superoxide production is more sensitive to the $\mathrm{pH}$ gradient across the inner mitochondrial membrane than to the membrane potential. This observation suggests an intimate connection with the proton pumping mechanism of complex I and hints at a contribution of the Qsite to superoxide production (Murphy, 2009). It is not clear if reverse electron transport can occur in vivo, and for plant tissues expressing alternative oxidase such a situation may be particularly unlikely, as the ubiquinone pool may be effectively oxidized before the critical threshold of ubiquinone reduction is reached. The total rate of superoxide production increases with the number of contributing complexes, i.e. complex I abundance, and the regulation thereof on the different levels described above. Mutant plants that lack complex I are therefore in principal expected to produce less superoxide in their mitochondria. Measurements of ROS and redox indicators in several different complex I mutants have suggested unchanged or even increased oxidative loads on the tissue level (Dutilleul et al., 2003a; He et al., 2012; Koprivova et al., 2010; Lee et al., 2002; Liu et al., 2010; Meyer et al., 2009). Those results may suggest increased rates of superoxide generation by other electron transfer chain complexes (such as complex III) due to the imbalance in electron flow in the absence of complex I. More importantly it is unclear, however, to which extent those data can be validly interpreted with respect to mitochondrial superoxide production due to very limited chemical or subcellular specificity of the employed methods. In principle complex I mediated superoxide production could increase dramatically, if fragments of the peripheral arm accumulate in a mutant and redox active sites that are normally embedded inside the complex are exposed. While partially assembled complex I fragments of the membrane arm have been detected in several mutants, none 
of the redox-active peripheral arm have been found thus far (Meyer et al., 2011). This could indicate that such a fragment has detrimental effects on plant viability and excessive ROS generation may contribute to lethality.

Superoxide generated at the FMN site of complex I will be released into the matrix and is unlikely to pass the inner membrane due to its negative charge at the alkaline $\mathrm{pH}$ of the matrix. In the matrix superoxide can undergo different fates: dismutation to $\mathrm{H}_{2} \mathrm{O}_{2}$ and $\mathrm{O}_{2}$, either spontaneously or catalyzed by $\mathrm{Mn}$-superoxide dismutase, reaction with other radicals such as NO (to give rise to $\mathrm{ONOO}^{-}$) or transition metal compounds, such as Fe-S clusters. By contrast, superoxide itself is not particularly reactive with proteins or DNA. Its mutagenic potential can therefore largely be ascribed to its downstream products. Other mitochondrial sites of superoxide generation include complex III, which can be a particularly stimulated by inhibition with antimycin A. Although that mode has been exploited extensively as model for mitochondrial ROS production, it is unclear to which extent complex III contributes to mitochondrial superoxide generation in vivo. Thus on the basis of the current, albeit sketchy picture, complex I is likely to be the main producer of matrix ROS in vivo under a wide range of conditions. The potential of complex I derived ROS to mediate transcriptional reprogramming has been assessed in plants using the inhibitor rotenone as well as genetic mutants (Dutilleul et al., 2003a; Garmier et al., 2008; Meyer et al., 2009; Schwarzlander et al., 2012). To separate out ROS-specific effects from other physiological changes remains a major challenge, however, one which has not yet been overcome. Combining the available resources of genetic complex I lines with novel in vivo ROS sensing techniques (Cocheme et al., 2011; Gutscher et al., 2009) and the structural models of complex I architecture (Baradaran et al., 2013; Klodmann et al., 2010) now provides the unique opportunity to dissect both the mechanisms and the physiological significance of ROS production by complex I in plants.

\section{Turnover, dis-assembly and degradation of complex I ("Old age and Death")}

Relatively little information is available on the degradation of complex I. It is clear that oxidoreductases such as complex I can get damaged easily due to the presence of reactive oxygen and nitrogen species or other reactive compounds which can arise during cellular respiration and further biochemical functions in the mitochondria. This raises the question if the entire complex I is degraded in case of damage of a single subunit, or if individual subunits can be replaced by functionally intact copies. Both mechanisms are known to occur in other protein complexes. Recent experiments using tagged complex I subunits have indicated that many but not all complex I subunits can be inserted into pre-existing complex I particles in human cell lines (Dieteren et al., 2012). However, for more extensively damaged complex I particles a complete degradation pathway is likely to exist. Based on isotope labelling experiments the half-life of OXPHOS complexes in plants is estimated to lie in the range of several days (Li et al., 2012; Nelson et al., 2013). Large protease complexes of the AAA family are known to specifically degrade protein complexes of the inner mitochondrial membrane. Complete protein degradation in mitochondria subsequently involves a set of different organelle-specific proteases including ATP-dependent proteases, processing peptidases, and oligopeptidases (for a recent review see Kwasniak et al., 2012). Since complex I is 1 MDa in molecular mass, its complete degradation substantially affects the amino acid pool sizes of the mitochondria (the currently known 49 subunits of Arabidopsis complex I sum up to about 9500 amino acids / complex I particle). The degradation products of a complex I that has been taken out of 
service thus replenish the amino acid pools that are required for a new life cycle of complex I to begin.

\section{Outlook}

Complex I of plants is of central importance for oxidative phosphorylation, is indirectly involved in both photorespiration and photosynthesis and includes additional auxiliary activities not directly related to energy metabolism. Its biogenesis is exceptionally complicated and sophisticated in plants (Figure 5). Mitochondrial phage-type polymerases are the first players to generate primary transcripts. Several nuclear encoded factors are required to remove numerous introns, including maturases which are partially encoded by the introns themselves. Nearly 200 nucleotide sites have to be edited which requires several additional factors, many of which belong to the large group of PPR proteins. Why is the generation of mature transcripts so amazingly complex in mitochondria of plants? Does this offer additional levels of regulation in assembly of plant complex I? Next, subunits of complex I are synthesized in two different cellular compartments, the mitochondria and the cytosol. Transport of polypeptides from the cytosol is particularly difficult in plants because strict discrimination between mitochondrial and chloroplastic import has to occur for all nuclear encoded complex I constituents. Finally, complex I assembly follows unique routes in plants and, at an early stage, requires carbonic anhydrase-related proteins which even form part of the holo-enzyme and contribute to its unique shape: an L-shaped particle with an additional central element (finally looking like a "lying F-shaped particle"). What is the significance of a protein of the ascorbate biosynthesis pathway to contribute to complex I assembly in plants? Complex I appears to act as a true multi-functional platform hosting and integrating a multitude of physiological processes of the plant cell.

Despite considerable efforts in research, many aspects of the biology of plant complex I are far from being understood. A broad and integrative research approach will be required if we are to tackle the most intriguing questions, some of which are outlined in the following paragraphs:

In vivo role of plant complex I

Future exploration of the versatility of complex I will be aided by the technical development of in vivo sensing techniques in mitochondria. Given its role as central hub of mitochondrial physiology, complex I regulation is likely to have direct impact on mitochondrial homeostasis. Redox state of the matrix NAD-pool, the proton motive force or ROS production depend directly on complex I characteristics, but also ATP/ADP ratio or redox status of the glutathione and ascorbate pools in the matrix are closely linked with complex I properties.

Matrix physiology can be expected to react particularly sensitively to changes in complex I characteristics, due to its relatively small volume as compared to the cytosol and its direct interaction with the complex. It is therefore of particular interest to measure changes in matrix physiology separately from those in other subcellular compartments. Current developments in quantitative imaging and a careful application of genetically-encoded fluorescent protein sensors will allow dissecting changes in physiology with subcellular resolution. Recently, fluorescent protein sensors for several key parameters of mitochondrial physiology have become available, covering ATP, NAD $\mathrm{H}_{2} \mathrm{O}_{2}, \mathrm{pH}$, calcium, and glutathione levels, some of which have already been adopted for measurements in planta (see recent summary by Gjetting et al., 2013). Applying such in vivo sensing 
techniques to the spectra of available complex I mutants holds the potential to resolve the exact place of complex I in the physiological network of plant mitochondria. While major consequences on whole cell physiology have been documented in mutants with severely reduced complex I abundance (Dutilleul et al., 2003a; Meyer et al., 2009), mitochondria-specific in vivo sensing techniques will allow measuring milder, yet physiologically meaningful, alterations, that would otherwise be obscured by effects from other parts of the cell. Being able to measure physiological parameters specifically and dynamically in the living cell and with subcellular resolution holds the opportunity to eventually unravel the exact functional impact that complex I regulation has in vivo (such as reversible supercomplex formation) on mitochondrial and cellular physiology.

Complex I as a site for metabolic channeling

Complex I in mammals binds several mitochondrial NAD-coupled dehydrogenase complexes including pyruvate dehydrogenase, $\alpha$-ketoglutarate dehydrogenase, the mitochondrial malate dehydrogenase (mMDH) and $\beta$-hydroxyacyl-CoA dehydrogenase (Sumegi and Srere, 1984). It has been proven that in the complex I- mMDH complex the NADH which is produced by mMDH is channelled to the binding site of complex I thereby avoiding diffusion via the bulk phase (Fukushima et al., 1989). Such channelling not only ensures an efficient traffic of NADH to the electron transport chain but additionally prevents both the consumption of NADH by competing enzymes and the inhibition of enzymes, for example the TCA cycle, by NADH. Intriguingly, the complex I - mMDH interaction of mammals is abolished by the addition of NADH in vitro (Fukushima et al., 1989) suggesting the possibility of regulating NADH metabolism by the transient binding of $\mathrm{mMDH}$ to complex I. To date studies on the association/disassociation of proteins to complexes of the mitochondrial electron transport chain in plants have largely been restricted to the interaction with L- galactono-1, 4-lactone dehydrogenase (GLDH, Pineau et al., 2008) and the formation of supercomplexes (Eubel et al., 2004). As described above, the interaction with GLDH had variously been reported to occur (Hervás et al., 2013; Schertl et al., 2012). By contrast, consensus has been reached regarding supercomplex formation in plants with several possible composition stoichiometries present and reports suggesting that these are responsive to environmental conditions (Ramírez-Aguilar et al., 2011). In addition, results of a recent study using BN/SDS-PAGE suggest that several mitochondrial enzymes including $N A D^{+}$-dependent malic enzyme and monodehydroascorbate reductase preferentially associate/disassociate to protein complexes under oxidative stress (Obata et al., 2011). Furthermore, clear evidence has been provided that the majority of NADH in plant mitochondria is bound to proteins (Kasimova et al., 2006). One possible explanation for this could potentially be the result of NADH channelling between complex I and mitochondrial dehydrogenases or even between different mitochondrial dehydrogenases. Indirect evidence for this hypothesis comes from complex I activity measurements in isolated mitochondria / inside out vesicles of submitochondrial particles in the presence of the channel-forming antibiotic alamethicin (Johansson et al, 2004). It seems likely that application of currently used experimental techniques such as co-purification and BN PAGE (used recently in characterizing the plant glycolytic metabolome; Giege et al., 2003; Graham et al., 2007) in addition to newly emerging techniques such as bimolecular complementation assays and structural prediction of protein binding surfaces as well as ever increasing spatial resolution of metabolic studies (Aharoni and Brandizzi, 2012; Steinhauser et al., 2012; Zhang et al., 2012) will prove highly informative in detecting protein association and metabolite channelling in and around complex I in plants. 
From our perspective, complex I lends itself as a highly suitable model system to study various molecular aspects of the plant cell: the maintenance of organelle homeostasis and the channelling of metabolites as outlined above, the interplay of respiration, photorespiration and photosynthesis and the coordination of protein biosynthesis machineries in the nuclear and the mitochondrial compartment.

\section{Acknowledgements}

This article summarizes contributions related to plant mitochondrial complex I presented at the $8^{\text {th }}$ International Conference on Plant Mitochondrial Biology (ICPMB) which was held from May 12 to 16 2013 in Rosario, Argentina. The authors wish to thank the organizing committee for arranging a wonderful conference. Furthermore, the authors thank the Center for Advanced Studies (CAS) of the Ludwig-Maximilians-University Munich for supporting the Symposium "The life of plant mitochondrial complex I" held in Munich on November 4/5, 2013. We thank Christine Schikowsky, Leibniz University Hannover/Germany, for the artwork of the article. Our research is supported by the Deutsche Forschungsgemeinschaft (grants BR1829-10/2 [HPB], BR326-11/1 [AB], FE552-9/2 [ARF], IF1655-1/1 [IF], SCHW 1719-1/1 [MS], TA624-2/2 [MT] and TA624-4/1 [MT]). 


\section{$\underline{\text { References }}$}

Abu-Abied, M., Avisar, D., Belausov, E., Holdengreber, V., Kam, Z., Sadot, E., 2009. Identification of an Arabidopsis unknown small membrane protein targeted to mitochondria, chloroplasts, and peroxisomes. Protoplasma 236, 3-12.

Aharoni, A., Brandizzi, F., 2012. High resolution methods in plant biology. Plant J. 70, 1-4.

Ahn, B.H., Kim, H.S., Song, S., Lee, I.H., Liu, J., Vassilopoulos, A., Deng, C.X., Finkel, T. 2008. A role for the mitochondrial deacetylase Sirt3 in regulating energy homeostasis. Proc. Natl. Acad. Sci. USA 105, 14447-14452.

Allen, R.D., Schroeder, A.K., Fok, A.K., 1989. An investigation of mitochondrial inner membranes by rapid-freeze deep-etch techniques. J. Cell Biol. 108, 2233-2240.

Angerer, H., Zwicker, K., Wumaier, Z., Sokolova, L., Heide, H., Steger, M., Kaiser, S., Nübel, E., Brutschy, B., Radermacher, M., Brandt, U., Zickermann, V., 2011. A scaffold of accessory subunits links the peripheral arm and the distal proton-pumping module of mitochondrial complex I. Biochem. J. 437, 279-288.

Antonicka, H., Ogilvie, I., Taivassalo, T., Anitori, R.P., Haller, R.G., Vissing, J., Kennaway, N.G., Shoubridge, E.A., 2003. Identification and characterization of a common set of complex I assembly intermediates in mitochondria from patients with complex I deficiency. J. Biol. Chem. 278, 43081-43088.

Arabidopsis Interactome Mapping Consortium, 2011. Evidence for network evolution in an Arabidopsis interactome map. Science 333, 601-607.

Balmer, Y., Vensel, W.H., Tanaka, C.K., Hurkman, W.J., Gelhaye, E., Rouhier, N., Jacquot, J.P., Manieri, W., Schurmann, P., Droux, M., Buchanan, B.B., 2004. Thioredoxin links redox to the regulation of fundamental processes of plant mitochondria. Proc. Natl. Acad. Sci. USA 101, 2642-2647.

Balsa, E., Marco, R., Perales-Clemente, E., Szklarczyk, R., Calvo, E., Landazuri, M.O. Enriquez, J.A., 2012. NDUFA4 is a subunit of complex IV of the mammalian electron transport chain. Cell Metab. 16, 378-386.

Baradaran, R., Berrisford, J.M., Minhas, G.S., Sazanov, L.A., 2013. Crystal structure of the entire respiratory complex I. Nature 494, 443-448.

Binder, S., Marchfelder, A., Brennicke, A., Wissinger, B., 1992. RNA editing in intron sequences may be required for trans-splicing of nad 2 transcripts in Oenothera mitochondria. J. Biol. Chem. 267, 7615-7623.

Bonen, L., 2008. Cis- and trans-splicing of group II introns in plant mitochondria. Mitochondrion 8 , 26-34.

Börner, G.V., Mörl, M., Wissinger, B., Brennicke, A., Schmelzer, C., 1995. RNA editing of a group II intron in Oenothera as a prerequisite for splicing. Mol. Gen. Genet. 246, 739-744.

Brandt, U., 2006. Energy converting NADH:quinone oxidoreductase (complex I). Annu. Rev. Biochem. 75, 69-92.

Brandt, U., 2013. Inside view of a giant proton pump. Angew. Chem. Int. Ed. Engl. 52, 7358-7360.

Brangeon, J., Sabar, M., Gutierres, S., Combettes, B., Bove, J., Gendy, C., Chetrit, P., Des Francs-Small, C.C., Pla, M., Vedel, F., De Paepe, R., 2000. Defective splicing of the first nad4 intron is associated with lack of several complex I subunits in the Nicotiana sylvestris NMS1 nuclear mutant. The Plant Journal 21, 269-280.

Braun, H.P., Zabaleta, E., 2007. Carbonic anhydrase subunits of the mitochondrial NADH dehydrogenase complex (complex I) in plants. Physiol. Plant. 129, 114-122.

Brennicke, A., Zabaleta, E., Dombrowski, S., Hoffmann, M., Binder, S., 1999. Transcription signals of mitochondrial and nuclear genes for mitochondrial proteins in dicot plants. J. Hered. 90, 345350.

Bultema, J., Braun, H.P., Boekema, E., Kouril, R., 2009. Megacomplex organization of the oxidative phosphorylation system by structural analysis of respiratory supercomplexes from potato. Biochim. Biophys. Acta 1787, 60-67. 
Bykova, N.V., Egsgaard, H., Møller, I.M., 2003. Identification of 14 new phosphoproteins involved in important plant mitochondrial processes. FEBS Lett. 540, 141-146.

Cardol, P., 2011. Mitochondrial NADH:ubiquinone oxidoreductase (complex I) in eukaryotes: a highly conserved subunit composition highlighted by mining of protein databases. Biochim. Biophys. Acta. 1807, 1390-1397.

Cardol, P., Vanrobaeys, F., Devreese, B., Van Beeumen, J., Matagne, R.F., Remacle, C., 2004. Higher plant-like subunit composition of mitochondrial complex I from Chlamydomonas reinhardtii: 31 conserved components among eukaryotes. Biochim. Biophys. Acta 1658, 212-224.

Carrie, C., Giraud, E., Duncan, O., Xu, L., Wang, Y., Huang, S., Clifton, R., Murcha, M., Filipovska, A., Rackham, O., Vrielink, A., Whelan, J., 2010. Conserved and novel functions for Arabidopsis thaliana MIA40 in assembly of proteins in mitochondria and peroxisomes. J. Biol. Chem. 285, 36138-36148.

Carroll, J., Fearnley, I.M., Skehel, J.M., Shannon, R.J., Hirst, J., Walker, J.E., 2006. Bovine complex I is a complex of 45 different subunits. J. Biol. Chem. 281, 32724-32727.

Cesaro, L., Salvi, M., 2010. Mitochondrial tyrosine phosphoproteome: new insights from an up-todate analysis. Biofactors 36, 437-450.

Chapdelaine, Y., Bonen, L., 1991. The wheat mitochondrial gene for subunit I of the NADH dehydrogenase complex: A trans-splicing model for this gene-in-pieces. Cell 65, 465-472.

Choi, B., Acero, M.M., Bonen, L., 2012. Mapping of wheat mitochondrial mRNA termini and comparison with breakpoints in DNA homology among plants. Plant Mol. Biol. 80, 539-552.

Chouchani, E.T., Methner, C., Nadtochiy, S.M., Logan, A., Pell, V.R., Ding, S., James, A.M., Cochemé, H.M., Reinhold, J., Lilley, K.S., Partridge, L., Fearnley, I.M., Robinson, A.J., Hartley, R.C., Smith, R.A., Krieg, T., Brookes, P.S., Murphy, M.P., 2013. Cardioprotection by S-nitrosation of a cysteine switch on mitochondrial complex I. Nat. Med. 19, 753-759.

Cocheme, H.M., Quin, C., McQuaker, S.J., Cabreiro, F., Logan, A., Prime, T.A., Abakumova, I., Patel, J.V., Fearnley, I.M., James, A.M., Porteous, C.M., Smith, R.A., Saeed, S., Carre, J.E., Singer, M., Gems, D., Hartley, R.C., Partridge, L., Murphy, M.P., 2011. Measurement of $\mathrm{H}_{2} \mathrm{O}_{2}$ within living Drosophila during aging using a ratiometric mass spectrometry probe targeted to the mitochondrial matrix. Cell Metab. 13, 340-350.

Dahm, C.C., Moore, K., Murphy, M.P., 2006. Persistent S-nitrosation of complex I and other mitochondrial membrane proteins by S-nitrosothiols but not nitric oxide or peroxynitrite: implications for the interaction of nitric oxide with mitochondria. J. Biol. Chem. 281, 1005610065.

De Longevialle, A.F., Meyer, E.H., Andres, C., Taylor, N.L., Lurin, C., Millar, A.H., Small, I.D., 2007. The pentatricopeptide repeat gene OTP43 is required for trans-splicing of the mitochondrial nad1 intron 1 in Arabidopsis thaliana. Plant Cell 19, 3256-3265.

De Rasmo, D., Signorile, A., Larizza, M., Pacelli, C., Cocco, T., Papa, S., 2012. Activation of the cAMP cascade in human fibroblast cultures rescues the activity of oxidatively damaged complex I. Free Radic. Biol. Med. 52, 757-764.

Dieteren, C.E., Koopman, W.J., Swarts, H.G., Peters. J.G., Maczuga, P., van Gemst, J.J., Masereeuw, R., Smeitink, J.A., Nijtmans, L.G., Willems, P.H, 2012. Subunit-specific incorporation efficiency and kinetics in mitochondrial complex I homeostasis. J. Biol. Chem. 287, 41851-41860.

Dombrowski, S., Hoffmann, M., Guha, C., Binder, S., 1999. Continuous primary sequence requirements in the 18-nucleotide promoter of dicot plant mitochondria. J. Biol. Chem. 274, 10094-10099.

Dudkina, N.V., Eubel, H., Keegstra, W., Boekema, E.J., Braun, H.P., 2005. Structure of a mitochondrial supercomplex formed by respiratory-chain complexes I and III. Proc. Natl. Acad. Sci. U.S.A 102, 3225-3229.

Dudkina, N.V., Kouril, R., Peters, K., Braun, H.P., Boekema, E.J., 2010. Structure and function of mitochondrial supercomplexes. Biochim. Biophys. Acta 1797, 664-670. 
Dutilleul, C., Garmier, M., Noctor, G., Mathieu, C., Chetrit, P., Foyer, C.H., de Paepe, R., 2003a. Leaf mitochondria modulate whole cell redox homeostasis, set antioxidant capacity, and determine stress resistance through altered signaling and diurnal regulation. Plant Cell 15, 1212-1226.

Dutilleul, C., Driscoll, S., Cornic, G., De Paepe, R., Foyer, C.H., Noctor, G., 2003b. Functional mitochondrial complex I is required by tobacco leaves for optimal photosynthetic performance in photorespiratory conditions and during transients. Plant Physiol. 131, 264-275.

Emanuelsson, O., Nielsen, H., Brunak, S., von Heijne, G., 2000. Predicting subcellular localization of proteins based on their N-terminal amino acid sequence. J. Mol. Biol. 300, 1005-1016.

Engelsberger, W.R., Schulze, W.X., 2012. Nitrate and ammonium lead to distinct global dynamic phosphorylation patterns when resupplied to nitrogen-starved Arabidopsis seedlings. Plant J. 69, 978-995.

Eubel, H., Jänsch, L., Braun, H.P., 2003. New insights into the respiratory chain of plant mitochondria. Supercomplexes and a unique composition of complex II. Plant Physiol. 133, 274-286.

Eubel, H., Heinemeyer, J., Braun, H.P., 2004. Identification and characterization of respirasomes in potato mitochondria. Plant Physiol. 134, 1450-1459.

Farré, J.-C., Aknin, C., Araya, A., B., C., 2012. RNA Editing in Mitochondrial Trans-Introns Is Required for Splicing. PLoS One 7, e52644.

Fey, J., Marechal-Drouard, L., 1999. Compilation and analysis of plant mitochondrial promoter sequences: An illustration of a divergent evolution between monocot and dicot mitochondria. Biochem. Biophys. Res. Commun. 256, 409-414.

Finkemeier, I., Laxa, M., Miguet, L., Howden, A.J., Sweetlove, L.J., 2011. Proteins of diverse function and subcellular location are lysine acetylated in Arabidopsis. Plant Physiol. 155, 1779-1790.

Fleischer, S., Brierley, G., Klouwen, H., Slautterback, D.G., 1962. The role of phospholipids in electron transfer. J. Biol. Chem. 237, 3264-3272.

Forner, J., Weber, B., Thuss, S., Wildum, S., Binder, S., 2007. Mapping of mitochondrial mRNA termini in Arabidopsis thaliana: t-elements contribute to 5 ' and 3 ' end formation. Nucleic Acids Res. 35, 3676-3692.

Fry, M., Green, D.E., 1981. Cardiolipin requirement for electron transfer in complex I and III of the mitochondrial respiratory chain. J. Biol. Chem. 246, 1874-1880.

Fukushima, T., Decker, R.V., Anderson, W.M., Spivey, H.O., 1989. Substrate channeling of NADH in mitochondrial redox processes. J. Biol. Chem. 264, 16483-16488.

Galkin, A., Moncada, S., 2007. S-nitrosation of mitochondrial complex I depends on its structural conformation. J. Biol. Chem. 282, 37448-37453.

Galkin, A., Meyer, B., Wittig, I., Karas, M., Schägger, H., Vinogradov, A., Brandt, U., 2008. Identification of the mitochondrial ND3 subunit as a structural component involved in the active/deactive enzyme transition of respiratory complex I. J. Biol. Chem. 283, 20907-20913.

Galkin, A., Abramov, A.Y., Frakich, N., Duchen, M.R., Moncada, S., 2009. Lack of oxygen deactivates mitochondrial complex I: implications for ischemic injury? J. Biol. Chem. 284, 36055-36061.

Garmier, M., Carroll, A.J., Delannoy, E., Vallet, C., Day, D.A., Small, I.D., Millar, A.H., 2008. Complex I dysfunction redirects cellular and mitochondrial metabolism in Arabidopsis. Plant Physiol. 148, 1324-1341.

Gawryluk, R.M., Gray, M.W., 2010. Evidence for an early evolutionary emergence of gamma-type carbonic anhydrases as components of mitochondrial respiratory complex I. BMC Evol. Biol. 10:176.

Gebert, N., Joshi, A.S., Kutik, S., Becker, T., McKenzie, M., Guan, X.L., Mooga, V.P., Stroud, D.A., Kulkarni, G., Wenk, M.R., Rehling, P., Meisinger, C., Ryan, M.T., Wiedemann, N., Greenberg, M.L., Pfanner, N., 2009. Mitochondrial Cardiolipin Involved in Outer-Membrane Protein Biogenesis: Implications for Barth Syndrome. Curr. Biol. 19, 2133-2139.

Giegé, P., Hoffmann, M., Binder, S., Brennicke, A., 2000. RNA degradation buffers asymmetries of transcription in Arabidopsis mitochondria. EMBO Rep. 1, 164-170. 
Giegé, P., Heazlewood, J.L., Roessner-Tunali, U., Millar, H., Fernie, A.R., Leaver, C.J., Sweetlove, L.J., 2003. Enzymes of Glycolysis Are Functionally Associated with the Mitochondrion in Arabidopsis Cells. Plant Cell 15, 2140-2151.

Giraud, E., Ng, S., Carrie, C., Duncan, O., Low, J., Lee, C.P., Van Aken, O., Millar, A.H., Murcha, M., Whelan, J., 2010. TCP transcription factors link the regulation of genes encoding mitochondrial proteins with the circadian clock in Arabidopsis thaliana. Plant Cell 22, 3921-3934.

Gjetting, S.K., Schulz, A., Fuglsang, A.T., 2013. Perspectives for using genetically encoded fluorescent biosensors in plants. Frontiers Plant Sci. 4, 234.

Graham, J.W.A., Williams, T.C.R., Morgan, M., Fernie, A.R., Ratcliffe, G., Sweetlove, L.J., 2007. Glycolytic Enzymes Associate Dynamically with Mitochondria in Response to Respiratory Demand and Support Substrate Channeling. Plant Cell 19, 3723-3738.

Gray, M.W., 2012. Mitochondrial evolution. Cold Spring Harb Perspect Biol. 4, a011403.

Grigorieff, N., 1998. Three-dimensional structure of bovine NADH:ubiquinone oxidoreductase (complex I) at 22Å in ice. J. Mol. Biol. 277, 1033-1046.

Guénebaut, V., Vincentelli, R., Mills, D., Weiss, H., Leonard, K.R., 1997. Three-dimensional structure of NADH-dehydrogenase from Neurospora crassa by electron microscopy and conical tilt reconstruction. J. Mol. Biol. 265, 409-418.

Gutscher, M., Sobotta, M.C., Wabnitz, G.H., Ballikaya, S., Meyer, A.J., Samstag, Y., Dick, T.P., 2009. Proximity-based protein thiol oxidation by H2O2-scavenging peroxidases. J. Biol. Chem. 284, 31532-31540.

Hager, J., Pellny, T.K., Mauve, C., Lelarge-Trouverie, C., De Paepe, R., Foyer, C.H., Noctor, G., 2010. Conditional modulation of NAD levels and metabolite profiles in Nicotiana sylvestris by mitochondrial electron transport and carbon/nitrogen supply. Planta 231, 1145-1157.

Haili, N., Arnal, N., Quadrado, M., Amiar, S., Tcherkez, G., Dahan, J., Briozzo, P., Colas des FrancsSmall, C., Vrielynck, N., Mireau, H., 2013. The pentatricopeptide repeat MTSF1 protein stabilizes the nad4 mRNA in Arabidopsis mitochondria. Nucleic Acids Res. 41, 6650-6663.

Håkansson, G., Allen, J.F. 1995. Histidine and tyrosine phosphorylation in pea mitochondria: evidence for protein phosphorylation in respiratory redox signaling. FEBS Lett. 372, 238-242.

Hartl, M., Finkemeier, I., 2012. Plant mitochondrial retrograde signaling: post-translational modifications enter the stage. Front Plant Sci. 3, 253.

Hatefi, Y., Haavik, A.G., Griffiths, D.E., 1962. Studies on the electron transfer system XL: Preparation and properties of mitochondrial DPNH-Coenzyme Q reductase. J. Biol. Chem. 237, 1676-1680.

Hatefi, Y., 1985. The mitochondrial electron transport and oxidative phosphorylation system. Ann. Rev. Biochem. 54, 1015-1069.

Hauler, A., Jonietz, C., Stoll, B., Stoll, K., Braun, H.P., Binder, S., 2013. RNA PROCESSING FACTOR 5 is required for efficient $5^{\prime}$ cleavage at a processing site conserved in RNAs of three different mitochondrial genes in Arabidopsis thaliana. Plant J. 74, 593-604.

He, J., Duan, Y., Hua, D., Fan, G., Wang, L., Liu, Y., Chen, Z., Han, L., Qu, L.J., Gong, Z., 2012. DEXH box RNA helicase-mediated mitochondrial reactive oxygen species production in Arabidopsis mediates crosstalk between abscisic acid and auxin signaling. Plant Cell 24, 1815-1833.

Heazlewood, J.L., Howell, K.A., Millar, A.H., 2003. Mitochondrial complex I from Arabidopsis and rice: orthologs of mammalian and fungal components coupled with plant-specific subunits. Biochim. Biophys. Acta 1604, 159-169.

Heazlewood, J.L., Tonti-Filippini, J.S., Gout, A.M., Day, D.A., Whelan, J., Millar, A.H., 2004. Experimental analysis of the Arabidopsis mitochondrial proteome highlights signaling and regulatory components, provides assessment of targeting prediction programs, and indicates plant-specific mitochondrial proteins. Plant Cell 16, 241-256.

Heazlewood, J.L., Durek, P., Hummel, J., Selbig, J., Weckwerth, W., Walther, D., Schulze, W.X., 2008. PhosPhAt: a database of phosphorylation sites in Arabidopsis thaliana and a plant-specific phosphorylation site predictor. Nucleic Acids Res. 36, D1015-1021.

Hervás, M., Bashir, Q., Leferink, N.G., Ferreira, P., Moreno-Beltrán, B., Westphal, A.H., Díaz-Moreno, I., Medina, M., de la Rosa, M.A., Ubbink, M., Navarro, J.A., van Berkel, W.J., 2013. 
Communication between (L)-galactono-1,4-lactone dehydrogenase and cytochrome c. FEBS. J. 280, 1830-1840.

Hoefs, S.J., Rodenburg, R.J., Smeitink, J.A., van den Heuvel, L.P., 2012. Molecular base of biochemical complex I deficiency. Mitochondrion 12, 520-532.

Hölzle, A., Jonietz, C., Törjek, O., Altmann, T., Binder, S., Forner, J., 2011. A RESTORER OF FERTILITYlike PPR gene is required for 5 '-end processing of the nad4 mRNA in mitochondria of Arabidopsis thaliana. Plant J. 65, 737-744.

Huang, S., Taylor, N.L., Whelan, J., Millar, A.H., 2009. Refining the definition of plant mitochondrial presequences through analysis of sorting signals, $\mathrm{N}$-terminal modifications, and cleavage motifs. Plant Physiol. 150, 1272-1285.

Hurd, T.R., Requejo, R., Filipovska, A., Brown, S., Prime, T.A., Robinson, A.J., Fearnley, I.M., Murphy, M.P., 2008. Complex I within oxidatively stressed bovine heart mitochondria is glutathionylated on Cys-531 and Cys-704 of the 75-kDa subunit: potential role of CYS residues in decreasing oxidative damage. J. Biol. Chem. 283, 24801-24815.

Ito, J., Taylor, N.L., Castleden, I., Weckwerth, W., Millar, A.H., Heazlewood, J.L., 2009. A survey of the Arabidopsis thaliana mitochondrial phosphoproteome. Proteomics 9, 4229-4240.

Jänsch, L., Kruft, V., Schmitz, U.K., Braun, H.P., 1996. New insights into the composition, molecular mass and stoichiometry of the protein complexes of plant mitochondria. Plant J. 9, 357-368.

Johansson, F.I., Michalecka, A.M., Møller, I.M., Rasmusson, A.G., 2004. Oxidation and reduction of pyridine nucleotides in alamethicin-permeabilized plant mitochondria. Biochem. J. 380, 193202.

Jonietz, C., Forner, J., Hölzle, A., Thuss, S., Binder, S., 2010. RNA PROCESSING FACTOR2 Is Required for 5 ' End Processing of nad9 and cox3 mRNAs in Mitochondria of Arabidopsis thaliana. Plant Cell 22, 443-453.

Juszczuk, I.M., Flexas, J., Szal, B., Dabrowska, Z., Ribas-Carbo, M., Rychter, A.M., 2007. Effect of mitochondrial genome rearrangement on respiratory activity, photosynthesis, photorespiration and energy status of MSC16 cucumber (Cucumis sativus) mutant. Physiol. Plant. 131, 527-541.

Kang, P.T., Zhang, L., Chen, C.L., Chen, J., Green, K.B., Chen, Y.R., 2012. Protein thiyl radical mediates S-glutathionylation of complex I. Free Radic. Biol. Med. 53, 962-973.

Kasimova, M.R., Grigiene, J., Krab, K., Hagedorn, P.H., Flyvbjerg, H., Andersen, P.E., Møller, I.M., 2006. The free NADH concentration is kept constant in plant mitochondria under different metabolic conditions. Plant Cell 18, 688-698.

Katayama, K., Sakurai, I., Wada, H., 2004. Identification of an Arabidopsis thaliana gene for cardiolipin synthase located in mitochondria. FEBS Lett. 577, 193-198.

Katayama, K., Wada, H., 2012. T-DNA Insertion in the CLS Gene for Cardiolipin Synthase Affects Development of Arabidopsis thaliana. Cytologica 77, 123-129.

Keren, I., Bezawork-Geleta, A., Kolton, M., Maayan, I., Belausov, E., Levy, M., Mett, A., Gidoni, D., Shaya, F., Ostersetzer-Biran, O., 2009. AtnMat2, a nuclear-encoded maturase required for splicing of group-II introns in Arabidopsis mitochondria. RNA 15, 2299-2311.

Keren, I., Tal, L., des Francs-Small, C.C., Araujo, W.L., Shevtsov, S., Shaya, F., Fernie, A.R., Small, I., Ostersetzer-Biran, O., 2012. nMAT1, a nuclear-encoded maturase involved in the trans-splicing of nad1 intron 1, is essential for mitochondrial complex I assembly and function. Plant J. 71, 413-426.

Klodmann, J., Sunderhaus, S., Nimtz, M., Jänsch, L., Braun, H.P., 2010. Internal architecture of mitochondrial complex I from Arabidopsis thaliana. Plant Cell 22, 797-810.

Klodmann, J., Braun, H.P., 2011. Proteomic approach to characterize mitochondrial complex I from plants. Phytochemistry 72, 1071-1080.

Klodmann, J., Rode, C., Senkler, M., Braun, H.P., 2011. The protein complex proteome of plant mitochondria. Plant Physiol. 157, 587-598.

Knoop, V., Schuster, W., Wissinger, B., Brennicke, A., 1991. Trans-splicing integrates an exon of 22 nucleotides into the nad5 mRNA in higher plant mitochondria. EMBO J. 10, 3483-3493. 
Kobayashi, Y., Knoop, V., Fukuzawa, H., Brennicke, A., Ohyama, K., 1997. Interorganellar gene transfer in bryophytes: The functional nad7 gene is nuclear encoded in Marchantia polymorpha. Mol. Gen. Genet. 256, 589-592.

Köhler, D., Schmidt-Gattung, S., Binder, S., 2010. The DEAD-box protein PMH2 is required for efficient group II intro splicing in mitochondria of Arabidopsis thaliana. Plant Mol. Biol. 72, 459-467.

König, A.C., Hartl, M., Pham, P.A., Laxa, M., Boersema, P., Orwat, A., Kalitventseva, I., Plöchinger, M., Braun, H.P., Leister, D., Mann, M., Wachter, A., Fernie, A., Finkemeier, I., 2014. The Arabidopsis class II sirtuin is a lysine deacetylase and interacts with mitochondrial energy metabolism. Plant Physiol., in press.

Koprivova, A., Colas des Francs-Small, C., Calder, G., Mugford, S.T., Tanz, S., Lee, B.-R., Zechmann, B., Small, I., Kopriva, S., 2010. Identification of a pentatricopeptide repeat protein implicated in splicing of intron 1 of mitochondrial nad7 transcripts. J. Biol. Chem. 285, 32192-32199.

Krause, F., Reifschneider, N.H., Vocke, D., Seelert, H., Rexroth, S., Dencher, N.A., 2004. "Respirasome"-like supercomplexes in green leaf mitochondria of spinach. J. Biol. Chem. 279, 48369-48375.

Kruft, V., Eubel, H., Jänsch, L., Werhahn, W., Braun, H.P., 2001. Proteomic approach to identify novel mitochondrial proteins in Arabidopsis. Plant Physiol. 127, 1694-1710.

Kühn, K., Weihe, A., Börner, T., 2005. Multiple promoters are a common feature of mitochondrial genes in Arabidopsis. Nucleic Acids Res. 33, 337-346.

Kühn, K., Bohne, A.V., Liere, K., Weihe, A., Börner, T., 2007. Arabidopsis phage-type RNA polymerases: accurate in vitro transcription of organellar genes. Plant Cell 19, 959-971.

Kühn, K., Richter, U., Meyer, E.H., Delannoy, E., Falcon de Longevialle, A., O'Toole, N., Börner, T., Millar, A.H., Small, I.D., Whelan, J., 2009. Phage-type RNA polymerase RPOTmp performs genespecific transcription in mitochondria of Arabidopsis thaliana. Plant Cell 21, 2762-2779.

Kühn, K., Carrie, C., Giraud, E., Wang, Y., Meyer, E.H., Narsai, R., des Francs-Small, C.C., Zhang, B., Murcha, M.W., Whelan, J., 2011. The RCC1 family protein RUG3 is required for splicing of nad2 and complex I biogenesis in mitochondria of Arabidopsis thaliana. Plant J. 67, 1067-1080.

Kwasniak, M., Pogorzelec, L., Migdal, I., Smakowska, E., Janska, H., 2012. Proteolytic system of plant mitochondria. Physiol. Plant. 145, 187-195.

Kwasniak, M., Majewski, P., Skibior, R., Adamowicz, A., Czarna, M., Sliwinska, E., Janska, H., 2013. Silencing of the Nuclear RPS10 Gene Encoding Mitochondrial Ribosomal Protein Alters Translation in Arabidopsis Mitochondria. Plant Cell 25, 1855-1867.

Lambert, A.J., Brand, M.D., 2004. Superoxide production by NADH:ubiquinone oxidoreductase (complex I) depends on the $\mathrm{pH}$ gradient across the mitochondrial inner membrane. Biochem. J. 382, 511-517.

Law, S.R., Narsai, R., Taylor, N.L., Delannoy, E., Carrie, C., Giraud, E., Millar, A.H., Small, I., Whelan, J., 2012. Nucleotide and RNA metabolism prime translational initiation in the earliest events of mitochondrial biogenesis during Arabidopsis germination. Plant Physiol. 158, 1610-1627.

Lazarou, M., McKenzie, M., Ohtake, A., Thorburn, D.R., Ryan, M.T., 2007. Analysis of the assembly profiles for mitochondrial- and nuclear-DNA-encoded subunits into complex I. Mol. Cell. Biol. 27, 4228-4237.

Lee, B.H., Lee, H., Xiong, L., Zhu, J.K., 2002. A mitochondrial complex I defect impairs cold-regulated nuclear gene expression. Plant Cell 14, 1235-1251.

Lee, C.P., Eubel, H., O'Toole, N., Millar, A.H., 2008. Heterogeneity of the mitochondrial proteome for photosynthetic and non-photosynthetic Arabidopsis metabolism. Mol. Cell. Proteomics 7, 1297-1316.

Lee, C.P., Eubel, H., O'Toole, N., Millar, A.H., 2011. Combining proteomics of root and shoot mitochondria and transcript analysis to define constitutive and variable components in plant mitochondria. Phytochemistry 72, 1092-1108.

Leon, S., Touraine, B., Ribot, C., Briat, J.F., Lobreaux, S., 2003. Iron-sulfur assembly in plant. Distinct NFU proteins in mitochondria and plastids from Arabidopsis thaliana. Biochem. J. 371, 823830. 
Leonard, K., Haiker, H., Weiss, H., 1987. Three-dimensional structure of NADH: ubiquinone reductase (complex I) from Neurospora mitochondria determined by electron microscopy of membrane crystals. J. Mol. Biol. 194, 277-286.

Li, L., Nelson, C.J., Solheim, C., Whelan, J., Millar, A.H., 2012. Determining degradation and synthesis rates of Arabidopsis proteins using the kinetics of progressive $15 \mathrm{~N}$ labeling of two-dimensional gel-separated protein spots. Mol. Cell. Proteomics 11, M111.010025.

Li, L., Nelson, C.J., Carrie, C., Gawryluk, R.M., Solheim, C., Gray, M.W., Whelan, J., Millar, A.H., 2013. Subcomplexes of ancestral respiratory complex I subunits rapidly turn over in vivo as productive assembly intermediates in Arabidopsis. J. Biol. Chem. 288, 5707-5717.

Liere, K., Weihe, A., Börner, T., 2011. The transcription machineries of plant mitochondria and chloroplasts: Composition, function, and regulation. J. Plant Physiol. 168, 1345-1360.

Liu, Y., He, J., Chen, Z., Ren, X., Hong, X., Gong, Z., 2010. ABA overly-sensitive 5 (ABO5), encoding a pentatricopeptide repeat protein required for cis-splicing of mitochondrial nad 2 intron 3 , is involved in the abscisic acid response in Arabidopsis. Plant J. 63, 749-765.

Lohrmann, J., Sweere, U., Zabaleta, E., Bäurle, I., Keitel, C., Kozma-Bognar, L., Brennicke, A., Schäfer, E., Kudla, J., Harter, K., 2001. The response regulator ARR2: a pollen-specific transcription factor involved in the expression of nuclear genes for components of mitochondrial complex $\mathrm{I}$ in Arabidopsis. Mol. Genet. Genomics 265, 2-13.

Masri, S., Patel, V.R., Eckel-Mahan, K.L., Peleg, S., Forne, I., Ladurner, A.G., Baldi, P., Imhof, A., Sassone-Corsi, P., 2013. Circadian acetylome reveals regulation of mitochondrial metabolic pathways. Proc. Natl. Acad. Sci. USA 110, 3339-3344.

Matsuo, M., Obokata, J., 2006. Remote control of photosynthetic genes by the mitochondrial respiratory chain. Plant J. 47, 873-882.

McKenzie, M., Lazarou, M., Thorburn, D.R., Ryan, M.T., 2006. Mitochondrial respiratory chain supercomplexes are destabilized in Barth syndrome patients. J. Mol. Biol. 361, 462-469.

Meyer, E.H., Heazlewood, J.L., Millar, A.H., 2007. Mitochondrial acyl carrier proteins in Arabidopsis thaliana are predominantly soluble matrix proteins and none can be confirmed as subunits of respiratory Complex I. Plant Mol. Biol. 64, 319-327.

Meyer, E.H., Taylor, N.L., Millar, A.H., 2008. Resolving and identifying protein components of plant mitochondrial respiratory complexes using three dimensions of gel electrophoresis. J. Prot. Res. 7, 786-794.

Meyer, E.H., Tomaz, T., Carroll, A.J., Estavillo, G., Delannoy, E., Tanz, S.K., Small, I.D., Pogson, B.J., Millar, A.H., 2009. Remodeled respiration in ndufs 4 with low phosphorylation efficiency suppresses Arabidopsis germination and growth and alters control of metabolism at night. Plant Physiol. 151, 603-619.

Meyer, E.H., Solheim, C., Tanz, S.K., Bonnard, G., Millar, A.H., 2011. Insights into the Composition and Assembly of the Membrane Arm of Plant Complex I through Analysis of Subcomplexes in Arabidopsis Mutant Lines. J. Biol. Chem. 286, 26081-26092.

Meyer, E.H., 2012. Proteomic investigations of complex I composition: how to define a subunit? Front Plant Sci. 3, 106.

Millar, A.H., Whelan, J., Soole, K.L., Day, D.A., 2011. Organization and regulation of mitochondrial respiration in plants. Annu. Rev. Plant Biol. 62, 79-104.

Mimaki, M., Wang, X., McKenzie, M., Thorburn, D.R., Ryan, M.T., 2012. Understanding mitochondrial complex I assembly in health and disease. Biochim. Biophys. Acta 1817, 851-862.

Mitchell, P., 1961. Coupling of phosphorylation to electron and hydrogen transfer by a chemiosmotic type of mechanism. Nature 191, 144-148.

Møller, I.M., Kristensen, B.K., 2006. Protein oxidation in plant mitochondria detected as oxidized tryptophan. Free Radic. Biol. Med. 40, 430-435.

Møller, I.M., Palmer, J.M., 1982. Direct evidence for the presence of a rotenone-resistant NADH dehydrogenase on the inner surface of the inner membrane of plant mitochondria. Physiol. Plant. 54, 267-274. 
Murcha, M.W., Elhafez, D., Lister, R., Tonti-Filippini, J., Baumgartner, M., Philippar, K., Carrie, C., Mokranjac, D., Soll, J., Whelan, J., 2007. Characterization of the preprotein and amino acid transporter gene family in Arabidopsis. Plant Physiol. 143, 199-212.

Murphy, M.P., 2009. How mitochondria produce reactive oxygen species. Biochem. J. 417, 1-13.

Narsai, R., Howell, K.A., Millar, A.H., O'Toole, N., Small, I., Whelan, J., 2007. Genome-wide analysis of mRNA decay rates and their determinants in Arabidopsis thaliana. Plant Cell 19, 3418-3436.

Narsai, R., Law, S.R., Carrie, C., Xu, L., Whelan, J., 2011. In-depth temporal transcriptome profiling reveals a crucial developmental switch with roles for RNA processing and organelle metabolism that are essential for germination in Arabidopsis. Plant Physiol. 157, 1342-1362.

Nehls, U., Friedrich, T., Schmiede, A., Ohnishi, T., Weiss, H., 1992. Characterization of assembly intermediates of NADH:ubiquinone oxidoreductase (complex I) accumulated in Neurospora mitochondria by gene disruption. J. Mol. Biol. 227, 1032-1042.

Nelson, C.J., Li, L., Jacoby, R.P., Millar, A.H., 2013. Degradation rate of mitochondrial proteins in Arabidopsis thaliana cells. J. Proteome Res. 12, 3449-3459.

Noctor, G., Dutilleul, C., De Paepe, R., Foyer, C.H., 2004. Use of mitochondrial electron transport mutants to evaluate the effects of redox state on photosynthesis, stress tolerance and the integration of carbon/nitrogen metabolism. J. Exp. Bot. 55, 49-57.

Obata, T., Matthes, A., Koszior, S., Lehmann, M., Araújo, W.L., Bock, R., Sweetlove, L.J., Fernie, A.R., 2011. Alteration of mitochondrial protein complexes in relation to metabolic regulation under short-term oxidative stress in Arabidopsis seedlings. Phytochemistry 72, 1081-1091.

Ogura, M., Yamaki, J., Homma, M.K., Homma, Y., 2012. Mitochondrial c-Src regulates cell survival through phosphorylation of respiratory chain components. Biochem. J. 447, 281-289.

Okada, S., Brennicke, A., 2006. Transcript levels in plant mitochondria show a tight homeostasis during day and night. Mol. Genet. Genomics 276, 71-78.

Pagniez-Mammeri, H., Rak, M., Legrand, A., Benit, P., Rustin, P., Slama, A., 2012. Mitochondrial complex I deficiency of nuclear origin II. Non-structural genes. Mol. Genet. Metab. 105, 173179.

Palmieri, M.C., Lindermayr, C., Bauwe, H., Steinhauser, C., Durner, J., 2010. Regulation of plant glycine decarboxylase by s-nitrosylation and glutathionylation. Plant Physiol. 152, 1514-1528.

Pellny, T.K., Van Aken, O., Dutilleul, C., Wolff, T., Groten, K., Bor, M., De Paepe, R., Reyss, A., Van Breusegem, F., Noctor, G., Foyer, C.H., 2008. Mitochondrial respiratory pathways modulate nitrate sensing and nitrogen-dependent regulation of plant architecture in Nicotiana sylvestris. The Plant Journal 54, 976-992.

Perales, M., Parisi, G., Fornasari, M.S., Colaneri, A., Villarreal, F., Gonzalez-Schain, N., Echave, J., Gomez-Casati, D., Braun, H.P., Araya, A. and Zabaleta, E., 2004. Gamma carbonic anhydrase like complex interact with plant mitochondrial complex I. Plant Mol. Biol. 56, 947-957.

Perales, M., Eubel, H. Heinemeyer, J., Colaneri, A., Zabaleta, E. Braun, H.P., 2005. Disruption of a nuclear gene encoding a mitochondrial gamma carbonic anhydrase reduces complex I and supercomplex $\mathrm{I}+\mathrm{III}_{2}$ levels and alters mitochondrial physiology in Arabidopsis. J. Mol. Biol. 350, 263-277.

Perrin, R., Meyer, E.H., Zaepfel, M., Kim, Y.J., Mache, R., Grienenberger, J.M., Gualberto, J.M., Gagliardi, D., 2004. Two exoribonucleases act sequentially to process mature 3'-ends of atp9 mRNAs in Arabidopsis mitochondria. J. Biol. Chem. 279, 25440-25446.

Peters, K., Dudkina, N.V., Jänsch, L., Braun, H.P., Boekema, E.J., 2008. A structural investigation of complex I and I+III2 supercomplex from Zea mays at 11-13 Á resolution: assignment of the carbonic anhydrase domain and evidence for structural heterogeneity within complex I. Biochim. Biophys. Acta 1777, 84-93.

Peters, K., Niessen, M., Peterhansel, C., Spath, B., Holzle, A., Binder, S., Marchfelder, A., Braun, H.P., 2012. Complex I-complex II ratio strongly differs in various organs of Arabidopsis thaliana. Plant Mol. Biol. 79, 273-284.

Peters, K., Belt, K., Braun, H.P., 2013. 3D Gel Map of Arabidopsis Complex I. Front Plant Sci. 4, 153. 
Pineau, B., Layoune, O., Danon, A., De Paepe, R., 2008. L-galactono-1,4-lactone dehydrogenase is required for the accumulation of plant respiratory complex I. J. Biol. Chem. 283, 32500-32505.

Pineau, B., Bourge, M., Marion, J., Mauve, C., Gilard, F., Maneta-Peyret, L., Moreau, P., SatiatJeunemaître, B., Brown, S.C., De Paepe, R., Danon, A., 2013. The importance of cardiolipin synthase for mitochondrial ultrastructure, respiratory function, plant development, and stress responses in Arabidopsis. Plant Cell, in press.

Priault, P., Tcherkez, G., Cornic, G., De Paepe, R., Naik, R., Ghashghaie, J., Streb, P., 2006. The lack of mitochondrial complex I in a CMSII mutant of Nicotiana sylvestris increases photorespiration through an increased internal resistance to CO2 diffusion. J. Exp. Bot. 57, 3195-3207.

Ramírez-Aguilar, S.J., Keuthe, M., Rocha, M., Fedyaev, V.V., Kramp, K., Gupta, K.J., Rasmusson, A.G., Schulze, W.X., van Dongen, J.T., 2011. The composition of plant mitochondrial supercomplexes changes with oxygen availability. J. Biol. Chem. 43045-43053.

Rardin, M.J., Newman, J.C., Held, J.M., Cusack, M.P., Sorensen, D.J., Li, B., Schilling, B., Mooney, S.D., Kahn, C.R., Verdin, E., Gibson, B.W. 2013. Label-free quantitative proteomics of the lysine acetylome in mitochondria identifies substrates of SIRT3 in metabolic pathways. Proc. Natl. Acad. Sci. USA 110, 6601-6606.

Rasmusson, A.G., Soole, K.L., Elthon, T.E., 2004. Alternative NAD(P)H dehydrogenases of plant mitochondria. Annu. Rev. Plant Biol. 55, 23-39.

Reiland. S., Messerli, G., Baerenfaller, K., Gerrits, B., Endler, A., Grossmann, J., Gruissem. W., Baginsky S., 2009. Large-scale Arabidopsis phosphoproteome profiling reveals novel chloroplast kinase substrates and phosphorylation networks. Plant Physiol. 150, 889-903.

Reiland, S., Finazzi, G., Endler, A., Willig, A., Baerenfaller, K., Grossmann, J., Gerrits, B., Rutishauser, D., Gruissem, W., Rochaix, J.D., Baginsky, S., 2011. Comparative phosphoproteome profiling reveals a function of the STN8 kinase in fine-tuning of cyclic electron flow (CEF). Proc. Natl. Acad. Sci. USA 108, 12955-12960.

Remacle, C., Barbieri, M.R., Cardol, P., Hamel, P.P., 2008. Eukaryotic complex I: functional diversity and experimental systems to unravel the assembly process. Mol. Genet. Genomics 280, 93110.

Rich, P., 2003. Chemiosmotic coupling: The cost of living. Nature 421, 583.

Rimmer, K.A., Foo, J.H., Ng, A., Petrie, E.J., Shilling, P.J., Perry, A.J., Mertens, H.D., Lithgow, T., Mulhern, T.D., Gooley, P.R., 2011. Recognition of mitochondrial targeting sequences by the import receptors Tom20 and Tom22. J. Mol. Biol. 405, 804-818.

Roberts, P.G., Hirst, J., 2012. The deactive form of respiratory complex I from mammalian mitochondria is a $\mathrm{Na}+\mathrm{H}+$ antiporter. J. Biol. Chem. 287, 34743-34751.

Rouhier, N., Villarejo, A., Srivastava, M., Gelhaye, E., Keech, O., Droux, M., Finkemeier, I., Samuelsson, G., Dietz, K.J., Jacquot, J.P., Wingsle, G., 2005. Identification of plant glutaredoxin targets. Antioxid. Redox Signal. 7, 919-929.

Sabar, M., De Paepe, R., de Kouchkovsky, Y., 2000. Complex I impairment, respiratory compensations, and photosynthetic decrease in nuclear and mitochondrial male sterile mutants of Nicotiana sylvestris. Plant Physiol. 124, 1239-1250.

Salvato, F., Havelund, J.F., Chen, M., Rao, R.S., Rogowska-Wrzesinska, A., Jensen, O.N., Gang, D.R., Thelen, J.J., Møller, I.M., 2014. The potato tuber mitochondrial proteome. Plant Physiol., in press

Salvi, M., Brunati, A.M., Toninello, A., 2005. Tyrosine phosphorylation in mitochondria: a new frontier in mitochondrial signaling. Free Radic. Biol. Med. 38, 1267-1277.

Sauve, A.A., 2010. Sirtuins. Biochim. Biophys. Acta 1804, 1565-1566.

Sazanov, L.A., Baradaran, R., Efremov, R.G., Berrisford, J.M., Minhas, G., 2013. A long road towards the structure of respiratory complex I, a giant molecular proton pump. Biochem. Soc. Trans. 41, 1265-1271.

Schägger, H., Pfeiffer, K., 2000. Supercomplexes in the respiratory chains of yeast and mammalian mitochondria. EMBO J. 19, 1777-1783. 
Schägger, H., 2002. Respiratory supercomplexes of mitochondria and bacteria. Biochim. Biophys. Acta 10, 154-159.

Schertl, P., Sunderhaus, S., Klodmann, J., Grozeff, G.E., Bartoli, C.G., Braun, H.P., 2012. L-galactono1,4-lactone dehydrogenase (GLDH) forms part of three subcomplexes of mitochondrial complex I in Arabidopsis thaliana. J. Biol. Chem. 287, 14412-14419.

Schlame, M., Rua, D., Greenberg, M.L., 2000. The biosynthesis and functional role of cardiolipin. Progr. Lipid Res. 39, 27-288.

Schleiff, E., Becker, T., 2011. Common ground for protein translocation: access control for mitochondria and chloroplasts. Nat. Rev. Mol. Cell Biol. 12, 48-59.

Schwarzländer, M., König, A.C., Sweetlove, L.J., Finkemeier, I., 2012. The impact of impaired mitochondrial function on retrograde signalling: a meta-analysis of transcriptomic responses. J. Exp. Bot. 63, 1735-1750.

Schwarzländer, M., Finkemeier, I., 2013. Mitochondrial energy and redox signaling in plants. Antioxid. Redox. Signal. 18, 2122-2144.

Senkler, M., Braun, H.P., 2012. Functional Annotation of 2D Protein Maps: The GelMap Portal. Front. Plant Sci. 3, 87.

Shikanai, T., 2007. Cyclic electron transport around photosystem I: genetic approaches. Annu. Rev. Plant. Biol. 58, 199-217.

Sol, E.M., Wagner, S.A., Weinert, B.T., Kumar, A., Kim, H.S., Deng, C.X., Choudhary, C., 2012. Proteomic investigations of lysine acetylation identify diverse substrates of mitochondrial deacetylase sirt3. PLoS One 7, e50545.

Soole, K.L., Dry, I.B., James, A.T., Wiskich, J.T., 1990. The kinetics of NADH oxidation by complex I of isolated plant mitochondria. Physiol. Plant. 80, 75-82.

Steinhauser, M.L., Bailey, A.P., Senyo, S.E., Guillermier, C., Perlstein, T.S., Gould, A.P., Lee, R.T., Lechene, C.P., 2012. Multi-isotope imaging mass spectrometry quantifies stem cell division and metabolism. Nature 481, 516-519.

Stern, D.B., Bang, A.G., Thompson, W.F. , 1986. The watermelon URF-1 gene: evidence for a complex structure. Curr. Genet. 10, 857-869.

Stoll, B., Stoll, K., Steinhilber, J., Jonietz, C., Binder, S., 2013. Mitochondrial transcript length polymorphisms are a widespread phenomenon in Arabidopsis thaliana. Plant Molecular Biology 81, 221-233.

Sumegi, B., Srere, P.A., 1984. Complex I binds several mitochondrial NAD-coupled dehydrogenases. J. Biol. Chem. 259, 15040-15045.

Sunderhaus, S., Dudkina, N., Jänsch, L., Klodmann, J., Heinemeyer, J., Perales, M., Zabaleta, E., Boekema, E., Braun, H.P., 2006. Carbonic anhydrase subunits form a matrix-exposed domain attached to the membrane arm of mitochondrial complex I in plants. J. Biol. Chem. 281, 64826488.

Takenaka, M., Verbitskiy, D., van der Merwe, J.A., Zehrmann, A., Brennicke, A., 2008. The process of RNA editing in plant mitochondria. Mitochondrion 8, 35-46.

Takenaka, M., Zehrmann, A., Verbitskiy, D., Häertel, B., Brennicke, A., 2013. RNA-Editing in plants and its evolution. Annu. Rev. Genet. In press.

Tanz, S., Castleden, I., Hooper, C.M., Vacher, M., Small, I., Millar, A.H., 2013. SUBA3: a database for integrating experimentation and prediction to define the SUBcellular location of proteins in Arabidopsis. Nuc. Acids Res. 41, D1185-1195.

Tian, G.W., Mohanty, A., Chary, S.N., Li, S., Paap, B., Drakakaki, G., Kopec, C.D., Li, J., Ehrhardt, D., Jackson, D., Rhee, S.Y., Raikhel, N.V., Citovsky, V., 2004. High-throughput fluorescent tagging of full-length Arabidopsis gene products in planta. Plant Physiol. 135, 25-38.

Ugalde, C., Vogel, R., Huijbens, R., Van Den Heuvel, B., Smeitink, J., Nijtmans, L., 2004. Human mitochondrial complex I assembles through the combination of evolutionary conserved modules: a framework to interpret complex I deficiencies. Hum. Mol. Genet. 13, 2461-2472.

Unseld, M., Marienfeld, J.R., Brandt, P., Brennicke, A., 1997. The mitochondrial genome of Arabidopsis thaliana contains 57 genes in 366,924 nucleotides. Nat. Genet. 15, 57-61. 
Van der Laan, M., Wiedemann, N., Mick, D.U., Guiad, B., Rehling, P., Pfanner, N., 2006. A role for Tim21 in membrane-potential-dependent preprotein sorting in mitochondria. Curr. Biol. 16, 2271-2276.

Vinogradov, A.D., 1998. Catalytic properties of the mitochondrial NADH-ubiquinone oxidoreductase (complex I) and the pseudo-reversible active/inactive enzyme transition. Biochim. Biophys. Acta 1364, 169-185.

Vogel, R.O., Dieteren, C.E., van den Heuvel, L.P., Willems, P.H., Smeitink, J.A., Koopman, W.J., Nijtmans, L.G., 2007a. Identification of mitochondrial complex I assembly intermediates by tracing tagged NDUFS3 demonstrates the entry point of mitochondrial subunits. J. Biol. Chem. $282,7582-7590$.

Vogel, R.O., Smeitink, J.A., Nijtmans, L.G., 2007b. Human mitochondrial complex I assembly: a dynamic and versatile process. Biochim. Biophys. Acta 1767, 1215-1227.

Wang, Q., Fristedt, R., Yu, X., Chen, Z., Liu, H., Lee, Y., Guo, H., Merchant, S.S., Lin, C., 2012a. The Ycarbonic anhydrase subcomplex of mitochondrial complex I is essential for development and important for photomorphogenesis of Arabidopsis. Plant Physiol. 160, 1373-1383.

Wang, Y., Carrie, C., Giraud, E., Elhafez, D., Narsai, R., Duncan, O., Whelan, J., Murcha, M., 2012b. Dual location of the mitochondria preprotein transporters B14.7 and Tim23-2 in complex I and the TIM17:23 complex in Arabidopsis links mitochondrial activity and biogenesis. Plant Cell 24, 2675-2695.

Watt, I.N., Montgomery, M.G., Runswick, M.J., Leslie, A.G., Walker, J.E., 2010. Bioenergetic cost of making an adenosine triphosphate molecule in animal mitochondria. Proc. Natl. Acad. Sci. USA 107, 16823-16827.

Welchen, E., Gonzalez, D.H., 2006. Overrepresentation of elements recognized by TCP-domain transcription factors in the upstream regions of nuclear genes encoding components of the mitochondrial oxidative phosphorylation Machinery. Plant Physiol. 141, 540-545.

Wissinger, B., Hiesel, R., Schuster, W., Brennicke, A., 1988. The NADH-dehydrogenase subunit 5 gene in Oenothera mitochondria contains two introns and is cotranscribed with the 18S-5S rRNA genes. Mol. Gen. Genet. 212, 56-65.

Wissinger, B., Schuster, W., Brennicke, A., 1991. Trans-splicing in Oenothera mitochondria: nad1 mRNAs are edited in exon and trans splicing group II intron sequences. Cell 65, 473-482.

Wittig, I., Carrozzo, R., Santorelli, F.M., Schägger, H., 2006. Supercomplexes and subcomplexes of mitochondrial oxidative phosphorylation. Biochim. Biophys. Acta 1757, 1066-1072.

Wu, X., Oh, M.H., Schwarz, E.M., Larue, C.T., Sivaguru, M., Imai, B.S., Yau, P.M., Ort, D.R., Huber, S.C., 2011. Lysine acetylation is a widespread protein modification for diverse proteins in Arabidopsis. Plant Physiol. 155, 1769-1778.

Yoshida, K., Noguchi, K., Motohashi, K., Hisabori, T., 2013. Systematic exploration of thioredoxin target proteins in plant mitochondria. Plant Cell Physiol. 54, 875-892.

Zabaleta, E., Martin, M.V., Braun, H.P., 2012. A basal carbon concentrating mechanism in plants? Plant Science 187, 97-104.

Zensen, R., Husmann, H., Schneider, R., Peine, T., Weiss, H., 1992. De novo synthesis and desaturation of fatty acids at the mitochondrial acyl-carrier protein, a subunit of NADH:ubiquinone oxidoreductase in Neurospora crassa. FEBS Lett. 310, 179-181.

Zhang X.P., Glaser E., 2001. Interaction of plant mitochondrial and chloroplast signal peptides with the Hsp70 molecular chaperone. Trends Plant Sci. 7, 14-21.

Zhang, M., Mileykowskaya, E., Dowhan, W., 2005. Cardiolipin is essential for organization of complexes III and IV into a supercomplex in intact yeast mitochondria. J. Biol. Chem. 280, 29403-29408.

Zhang, D.S., Piazza, V., Perrin, B.J., Rzadzinska, A.K., Poczatek, J.C., Wang, M., Prosser, H.M., Ervasti, J.M., Corey, D.P., Lechene, C.P. 2012. Multi-isotope imaging mass spectrometry reveals slow protein turnover in hair-cell stereocilia. Nature 481, 520-524.

Zmudjak, M., Colas des Francs-Small, C., Keren, I., Shaya, F., Belausov, E., Small, I., Ostersetzer-Biran, O., 2013. mCSF1, a nucleus-encoded CRM protein required for the processing of many 
mitochondrial introns, is involved in the biogenesis of respiratory complexes I and IV in Arabidopsis. New Phytol. 199, 379-394.

\section{$\underline{\text { Tables }}$}

Table 1: Proteins involved in complex I gene transcription, transcript splicing and transcript end maturation in plant mitochondria

\begin{tabular}{|c|c|c|c|c|c|}
\hline $\begin{array}{l}\text { Functional } \\
\text { category }\end{array}$ & Gene family & Gene $^{1}$ & AGI & Target transcript $(\mathrm{Cl})$ & Reference \\
\hline Transcription & $\begin{array}{l}\text { Phage-type RNA } \\
\text { polymerase }\end{array}$ & RPOTm & At1g68990 & $\begin{array}{l}\text { nad1, nad2, nad3, nad4, } \\
\text { nad4L, nad5, nad6, nad7, } \\
\text { nad9 }\end{array}$ & Kühn et al., 2009 \\
\hline Transcription & $\begin{array}{l}\text { Phage-type RNA } \\
\text { polymerase }\end{array}$ & RPOTmp & At5g15700 & $\begin{array}{l}\text { nad1, nad2, nad4, nad4L, } \\
\text { nad5, nad6, nad9 }\end{array}$ & Kühn et al., 2009 \\
\hline Splicing & PPR family & OTP43 & At1g74900 & nad1 & $\begin{array}{l}\text { Falcon de Longevialle et al., } \\
2007\end{array}$ \\
\hline Splicing & PPR family & BIR6 & At3g48250 & nad7 & Koprivova et al., 2010 \\
\hline Splicing & PPR family & $A B O 5$ & At1g51965 & nad2 & Liu et al., 2010 \\
\hline Splicing & RNA helicase & PMH2 & At3g22330 & $\begin{array}{l}\text { nad1, nad2, nad4, nad5, } \\
\text { nad7, others }\end{array}$ & Köhler et al., 2010 \\
\hline Splicing & RNA helicase & $A B 06$ & At5g04895 & nad1, nad2, nad4, nad5 & He et al., 2012 \\
\hline Splicing & RCC1-like & RUG3 & At5g60870 & nad2 & Kühn et al., 2011 \\
\hline Splicing & $\begin{array}{l}\text { gene not } \\
\text { identified }\end{array}$ & NMS1 & & nad4 & Brangeon et al., 2000 \\
\hline Splicing & RNA maturase & MAT1 & At1g30010 & nad1, nad2, nad4 & Keren et al., 2012 \\
\hline Splicing & RNA maturase & MAT2 & At5g46920 & nad1, nad7 & Keren et al., 2009 \\
\hline Splicing & $\begin{array}{l}\text { CRM-domain } \\
\text { family }\end{array}$ & $m C S F 1$ & At4g31010 & $\begin{array}{l}\text { nad1, nad2, nad4, nad5, } \\
\text { nad7, others }\end{array}$ & Zmudjak et al., 2013 \\
\hline Splicing & PPR family & MTSF1 & At1g06710 & nad2 & Haili et al., 2013 \\
\hline End maturation & PPR family & MTSF1 & At1g06710 & nad4 & Haili et al., 2013 \\
\hline End maturation & $\begin{array}{l}\text { PPR family, P- } \\
\text { class }\end{array}$ & RPF1 & At1g12700 & nad4 & Hölzle et al., 2011 \\
\hline End maturation & $\begin{array}{l}\text { PPR family, P- } \\
\text { class }\end{array}$ & RPF2 & At1g62670 & nad9, $\operatorname{cox} 2$ & Jonietz et al., 2010 \\
\hline End maturation & $\begin{array}{l}\text { PPR family, P- } \\
\text { class }\end{array}$ & RPF5 & At4g28010 & nad6, atp9, 26S rRNA & Hauler et al., 2013 \\
\hline End maturation & $\begin{array}{l}\text { gene not } \\
\text { identified }\end{array}$ & RPF7 & & nad2 & Stoll et al., 2013 \\
\hline
\end{tabular}

${ }^{1}$ Excepting NMS1 described in Nicotiana sylvestris, all listed genes were identified in Arabidopsis thaliana. 
Table 2: Total numbers of RNA editing sites in coding regions of complex I mRNAs in mitochondria of Arabidopsis thaliana

\begin{tabular}{|c|c|}
\hline Mt gene & $\begin{array}{c}\text { No. of editing } \\
\text { sites }\end{array}$ \\
\hline nad1 & 22 \\
\hline nad2 & 29 \\
\hline nad3 & 11 \\
\hline nad4 & 35 \\
\hline nad4L & 9 \\
\hline nad5 & 31 \\
\hline nad6 & 11 \\
\hline nad7 & 29 \\
\hline nad9 & 7 \\
\hline matR & 10 \\
\hline Total & 194 \\
\hline
\end{tabular}

Table 3: RNA editing sites in complex I mRNAs to which PPR type RNA editing factors have been assigned in mitochondria of Arabidopsis thaliana

\begin{tabular}{|c|c|c|c|c|}
\hline Mt gene & $\begin{array}{l}\text { Position } \\
\text { from ATG }\end{array}$ & Editing factor & AGI acc. & PPR type \\
\hline nad1 & 308 & MEF25 & At3g25060 & $E$ \\
\hline nad1 & 571 & MEF32 & At4g14170 & $E$ \\
\hline nad2 & 558 & REME1 & At2g03880 & DYW \\
\hline nad2 & 842 & MEF10 & At3g11460 & DYW \\
\hline nad2 & 1160 & MEF1 & At5g52630 & DYW \\
\hline nad2 & 1433 & MEF7 & At5g09950 & DYW \\
\hline nad3 & 149 & MEF22 & At3g12770 & DYW \\
\hline nad3 & 250 & SLG1 & At5g08490 & $E$ \\
\hline nad4 & 124 & MEF11 & At4g14850 & DYW \\
\hline nad4 & 376 & AHG11 & At2g44880 & $E$ \\
\hline nad4 & 449 & SLO1 & At2g22410 & $E$ \\
\hline nad4 & 1355 & MEF18 & At5g19020 & $E$ \\
\hline nad4L & 41 & MEF7 & At5g09950 & DYW \\
\hline nad4L & 110 & SLO2 & At2g13600 & $E$ \\
\hline nad5 & 374 & MEF12 & At3g09040 & $E$ \\
\hline nad5 & 676 & MEF8 & At2g25580 & DYW \\
\hline nad5 & 1550 & MEF29 & At4g30700 & DYW \\
\hline nad6 & 95 & MEF8 & At2g25580 & DYW \\
\hline nad7 & 24 & OTP87 & At1g74600 & $E$ \\
\hline nad7 & 200 & MEF9 & At1g62260 & $\mathrm{E}$ \\
\hline nad7 & 739 & SLO2 & At2g13600 & $E$ \\
\hline nad7 & 963 & MEF1 & At5g52630 & DYW \\
\hline nad9 & 328 & SLO1 & At2g22410 & $\mathrm{E}$ \\
\hline matR & 1730 & MEF11 & At4g14850 & DYW \\
\hline matR & 1895 & MEF14 & At3g26780 & DYW \\
\hline
\end{tabular}




\section{$\underline{\text { Figures }}$}

\section{Figure 1}

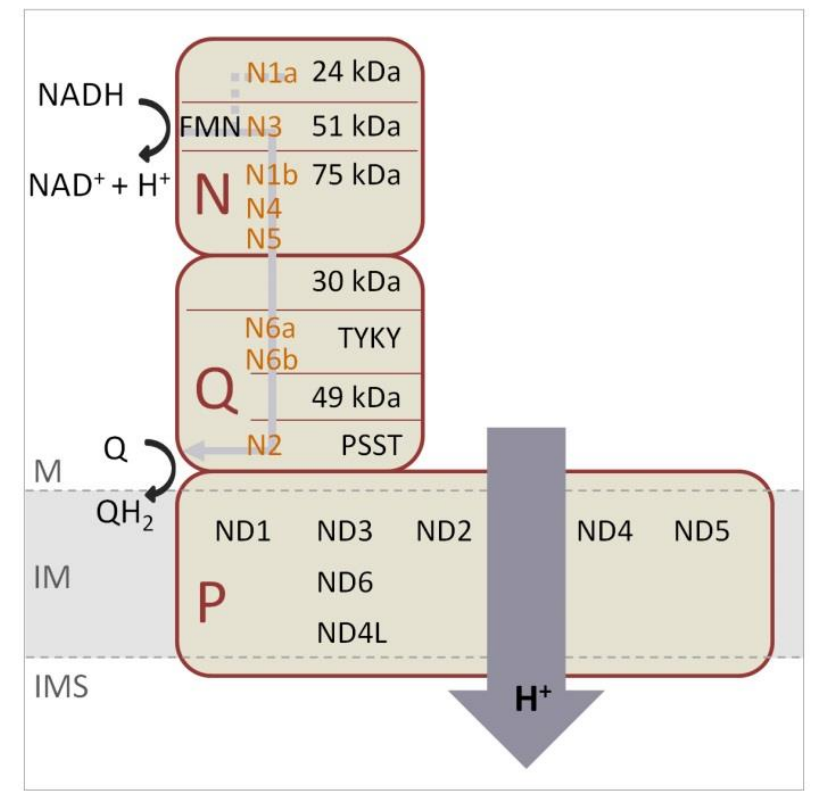

Figure 1: Modular design of complex I. $\mathrm{N}=\mathrm{NADH}$ oxidation module, $\mathrm{Q}=$ Quinone reduction module, $\mathrm{P}=$ Proton translocation module. Core subunits of each module are indicated (black) as well as respective FeS cluster(s) (orange). The NADH oxidation site (FMN) is located at the $51 \mathrm{kDa}$ subunit. Electron flow through the peripheral arm and proton translocation across the membrane arm are indicated by grey arrows. M: matrix, IM: inner membrane, IMS: inter-membrane space.

Figure 2

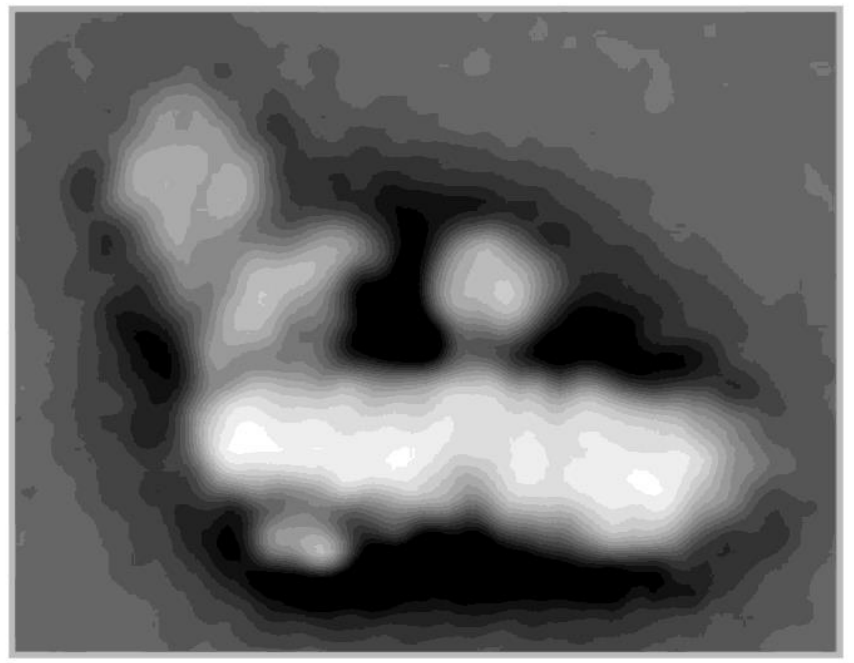

Figure 2: Averaged structure of mitochondrial complex I from Arabidopsis thaliana. Isolated complex I was stained by uranyl acetate and images were taken by transmission electron microscopy (from: Sunderhaus et al., 2006, J. Biol. Chem. 281, 6482-6488, with permission) 
Figure 3

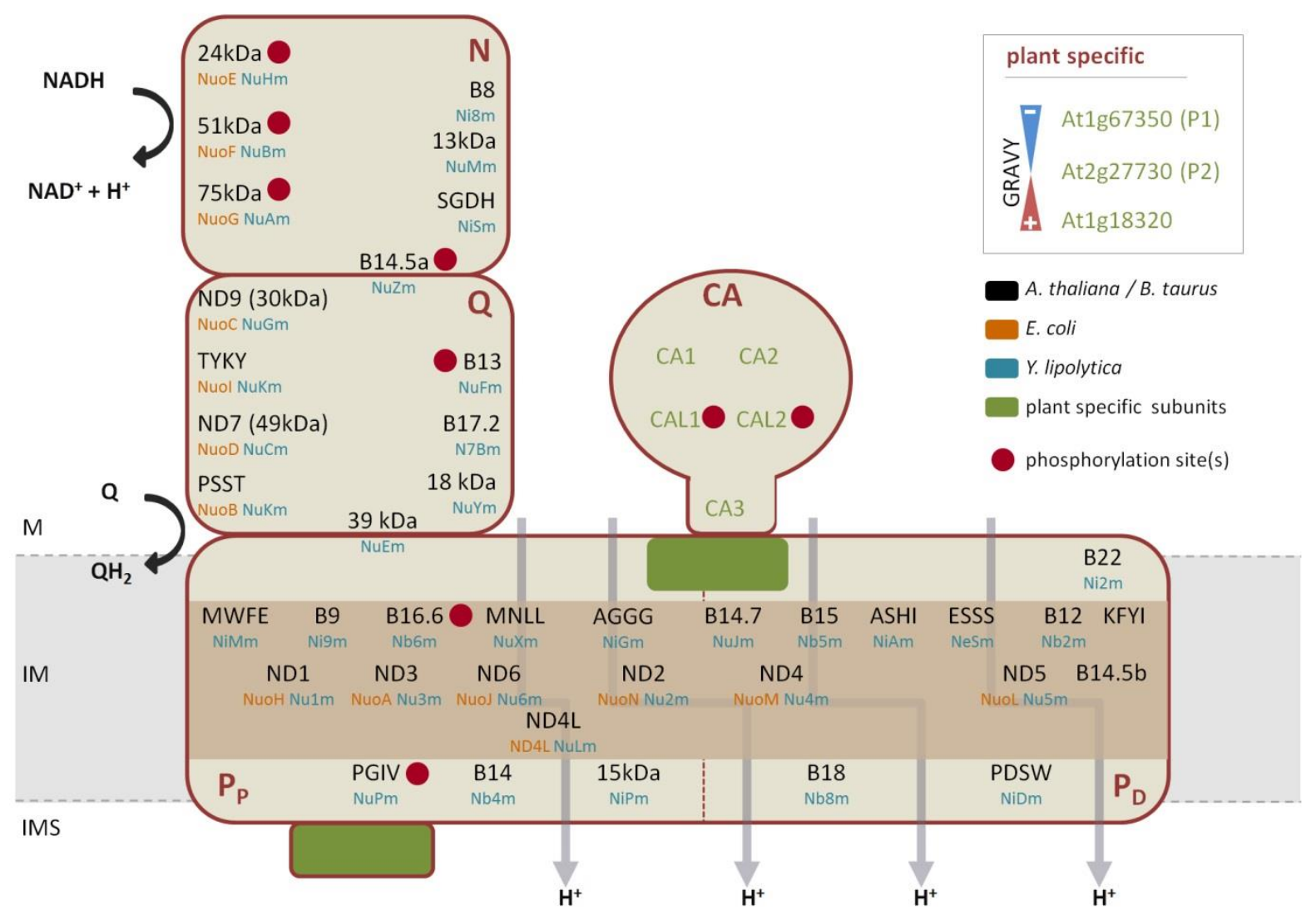

Figure 3: Model of the internal subunit arrangement of plant complex I. The P-module contains two domains: one proximal to the peripheral arm $\left(P_{\mathrm{P}}\right)$, the other one on distal side $\left(\mathrm{P}_{\mathrm{D}}\right)$ (Angerer et al., 2011). Subunits are named according to the bovine nomenclature (black), which also has been used for Arabidopsis (see Supp. table 1). Furthermore, names of homologs in E. coli (orange) and $Y$. lipolytica (blue) are indicated. Besides the carbonic anhydrases subunits (CA domain), positions of plant specific subunits are not clear so far. Therefore, these subunits are listed in the box above the scheme according to their GRAVY scores (which indicates tendencies for peripheral [negative scores] or integral positions [positive score]). In the model, possible locations of these subunits are indicated in green. Membrane-spanning subunits of the membrane arm are given in the center of this domain, subunits localized more peripherally within the membrane are given above and below (beige background). Phosphorylated subunits are marked by red dots (for details see Supp. table 5). M: matrix, IM: inner membrane, IMS: inter membrane space. 
Figure 4

re-oxidation of mt NADH produced by the TCA cycle, photorespiration, amino acid catabolism etc.

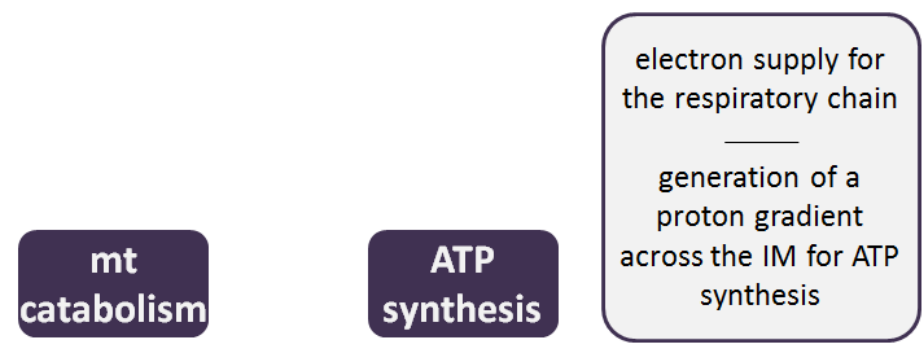

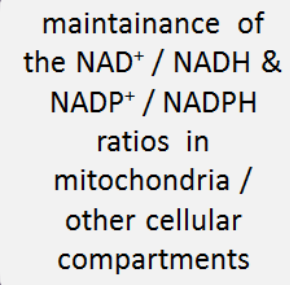

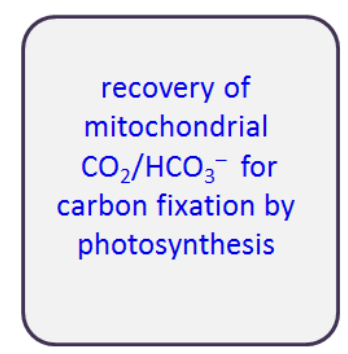

\section{carbon \\ fixation}
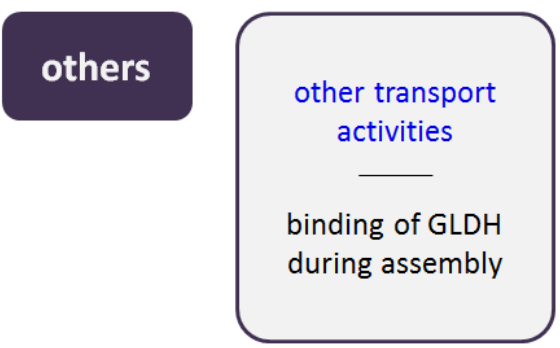

Figure 4: Functions (black) and putative functions (blue) of mitochondrial complex I in plants. mt: mitochondrial, IM: inner mitochondrial membrane, GLDH: L-galactono-1,4-lactone dehydrogenase 
Figure 5 (Summary)

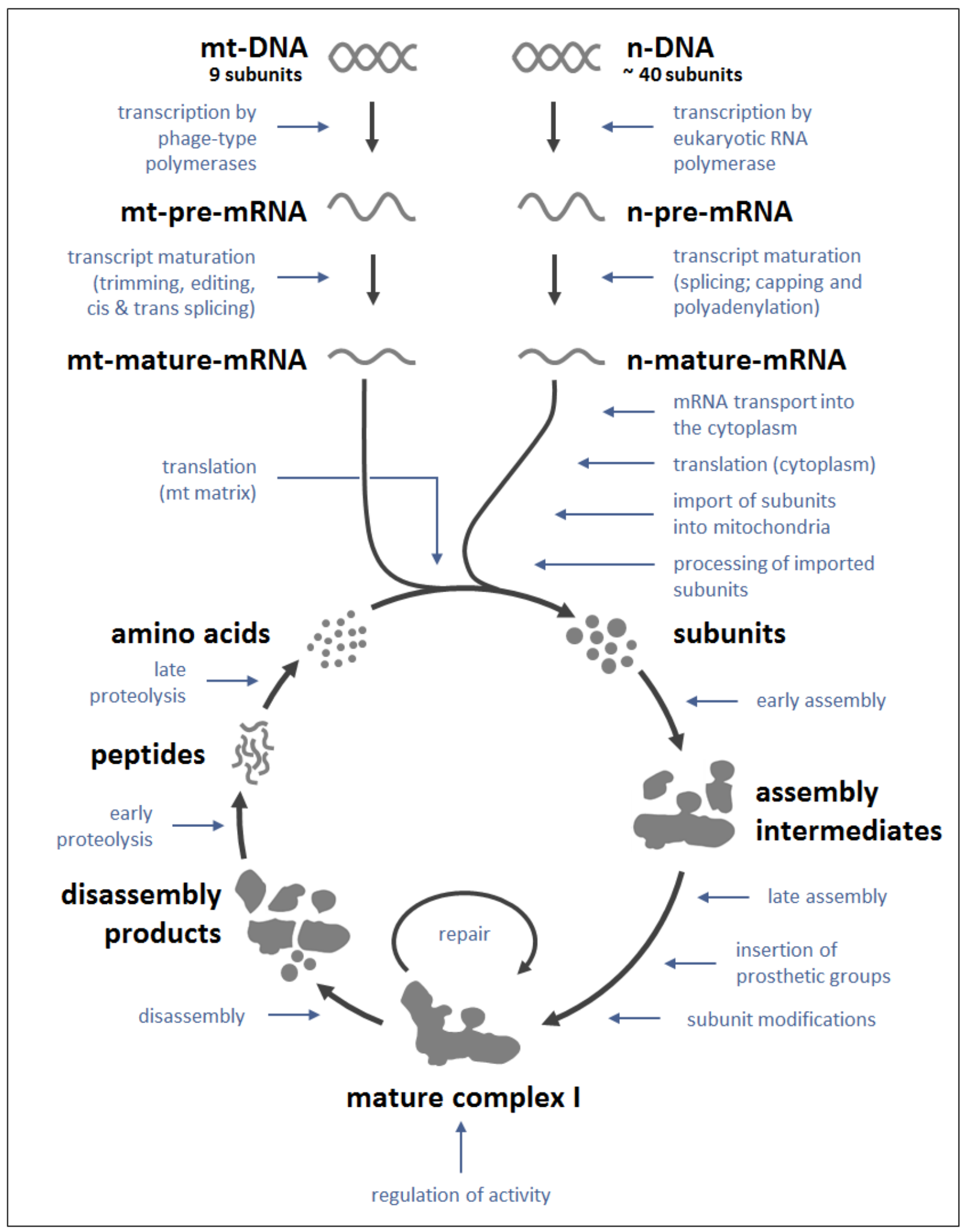

Figure 5: Life cycle of mitochondrial complex I in plants. mt: mitochondrial, n: nuclear 